\title{
High Oxidation State Organomolybdenum and Organotungsten Chemistry in Protic Environments
}

\author{
Rinaldo Poli \\ Laboratoire de Chimie de Coordination, UPR CNRS 8241 liée par convention à l'Université Paul \\ Sabatier et à l'Institut National Polytechnique de Toulouse, 205 Route de Narbonne, 31077 Toulouse, \\ France; Fax: (+) 33-561553003; E-mail: Rinaldo.Poli@lcc-toulouse.fr
}




\section{Summary}

The chemistry of organomolybdenum and -tungsten compounds in high oxidation states (mostly V and VI) is reviewed, with special attention on the behaviour in protic media and with respect to protic reagents. The high metal-carbon bond covalency imparts a great degree of inertness to these bonds relative to protonolysis. Hence, extensive chemistry in a wide variety of media and with protic reagents is possible without affecting the metal-(hydrocarbyl ligand) interactions. This article does not cover metallocene [i.e. bis(cyclopentadienyl)], alkylidene and alkylidyne derivatives, that have been extensively covered in other recent reviews.

Keywords: Molybdenum, Tungsten, Alkyl ligands, Cyclopentadienyl ligands, Oxido ligands, Aqueous organometallic chemistry 
Index

1. Introduction 4

2. Alkyl and Aryl Compounds $\quad 7$

3. $\pi$-Allyl Compounds 9

4. Cyclopentadienyl Compounds 10

$\begin{array}{ll}\text { 4.1. Synthetic aspects } & 10\end{array}$

$\begin{array}{ll}\text { 4.2. Speciation studies } & 21\end{array}$

4.3. Reductive chemistry 23

4.4. Other reactions 33

5. Conclusion 45

6. Acknowledgement 46

$\begin{array}{ll}\text { 7. References } & 47\end{array}$ 


\section{Introduction}

Although organometallic chemistry is mostly developed in the low oxidation states, high oxidation state organometallics are also common. They comprise homoleptic compounds such as $\left[\mathrm{W}\left(\mathrm{CH}_{3}\right)_{6}\right][1]$ and $\left[\mathrm{Re}\left(\mathrm{CH}_{3}\right)_{8}\right]^{2-}[2]$, and complexes that also contain other electronegative ligands, such as oxido (e.g. $\left[\mathrm{Cp}^{*} \mathrm{ReO}_{3}\right]$ [3] and $\left[\mathrm{CH}_{3} \mathrm{ReO}_{3}\right]$ [4]), halido (e.g. $\left.\left[\mathrm{Cp}^{*} \mathrm{WF}_{5}\right][5]\right)$, imido (e.g. $\left[(t \mathrm{BuN})_{3} \operatorname{Re}(\mathrm{Ar})\right]$ with $\mathrm{Ar}=o$-tol, xylyl and mes [6]), nitrido (e.g. $\left[\mathrm{Mo}(\mathrm{N})\left(\mathrm{CH}_{2} \mathrm{CMe}_{3}\right)_{3}\right]$ [7]), etc. The elevated Lewis acidity of high oxidation state metals is not fully satisfied by the metal-carbon bonds alone, thus the homoleptic compounds are typically quite unstable and reactive. For instance, compounds $\left[\mathrm{W}\left(\mathrm{CH}_{3}\right)_{6}\right][1]$ and $\left[\mathrm{Re}\left(\mathrm{CH}_{3}\right)_{6}\right]$ [2] thermally decompose at room temperature or below and react rapidly with water and other compounds containing acidic hydrogens to give methane. On the other hand, $\pi$-donor (e.g. O-, $\mathrm{N}$-based) ancillary ligands, even though poorer $\sigma$ donors because of their greater electronegativity relative to carbon, impart greater stability to the resulting complexes rendering them less susceptible to decomposition or oxidative/hydrolytic reactions. Since metal-carbon bonds with X-type [8] organic ligands (X: alkyl, aryl; XL: allyl; $\mathrm{XL}_{2}$ : pentadienyl, cyclopentadienyl) enjoy a high degree of covalency when the metal is in a high oxidation state, they become less susceptible to hydrolytic decomposition and more resistant to oxidative degradation in air. Conversely, M-L bonds (L: olefins, $\mathrm{L}_{2}$ : dienes, $\mathrm{L}_{3}$, arenes), which largely rely on back bonding for stabilization, are less and less compatible with the higher oxidation states, so that high oxidation state organometallic chemistry is more or less restricted to X-type ligands. In combination with ancillary ligands that resist hydrolytic decomposition, the compounds may become stable in an aqueous environment. As an illustrative example from the early literature, compound $\left[\mathrm{CpMoCl}_{4}\right]$ is rapidly hydrolyzed to $\left[\mathrm{CpMoO}_{2}\right]_{2}$ which is stable in water [9]. Thus, the reagent $\mathrm{Mo}^{\mathrm{V}}-\mathrm{Cl}$ bonds are hydrolytically 
sensitive, but less so than the $\mathrm{Mo}^{\mathrm{V}}-\mathrm{Cp}$ bond, whereas all bonds in the final product withstand an aqueous environment.

From the above arguments, it can be concluded that organometallic compounds containing metal carbon bonds of M-X type (e.g. alkyl, aryl, allyl, pentadienyl ligands) may be compatible with protic reagents and solvents (e.g. water or aqueous solvents) in the high oxidation states. Furthermore, injecting electrons into these systems increases the basicity of ancillary ligands, favouring their protonation. For the particular case of oxido ligands, their conversion to hydroxido and aqua ligands (see Scheme 1) might open the way to the possible use of hydrosoluble organometallic complexes in electrocatalytic applications, in view of the facile dissociation of water with liberation of an open coordination site for substrate binding and activation.

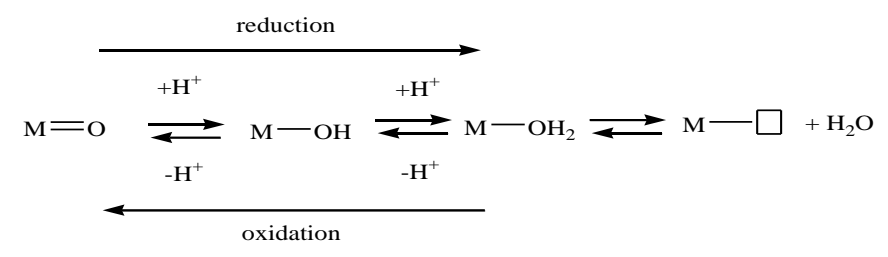

\section{Scheme 1}

This review covers high oxidation state organometallic chemistry with particular emphasis on processes where protic reagents or solvents are used and is limited to the Group 6 elements molybdenum and tungsten. Although examples of organometallic oxido derivatives of $\mathrm{Cr}^{\mathrm{V}}$ and $\mathrm{Cr}^{\mathrm{VI}}$ have been described (e.g. $\left[\mathrm{Cp}^{*} \mathrm{CrO}_{2}\right]_{2}[10],\left[\mathrm{Cp} * \mathrm{CrO}\left(\mathrm{CH}_{3}\right)_{2}\right]$ and $\left.\left[\mathrm{Cp}^{*} \mathrm{CrO}_{2}\left(\mathrm{CH}_{3}\right)\right][11]\right)$, their chemistry has been much less developed and first principles suggest that they will be less compatible with protic reagents than their Mo and $\mathrm{W}$ analogues.

Within Mo and W chemistry, most studies have been focused on mono- and bis(cyclopentadienyl) derivatives. The aqueous chemistry of bis(cyclopentadienyl)molybdenum derivatives (molybdocenes) has been developed extensively, particularly by D. R. Tyler, and a review of this work has recently appeared in this journal [12], whereas related 
tungsten systems have been much less investigated in protic environments [13-15]. This family of materials will be excluded from the present review. We just wish to underline here the hydrolytic stability of the $\left[\mathrm{Cp}_{2} \mathrm{Mo}\right]^{2+}$ moiety, no $\mathrm{Cp}$ loss being detected at neutral $\mathrm{pH}$ over a period of several weeks. The facile dissociation of chlorides from the readily available $\left[\mathrm{Cp}_{2} \mathrm{MoCl}_{2}\right]$ [16] and the acidity of the resulting molybdocene ion in water [17], giving the charged complexes $\left[\mathrm{Cp}_{2} \mathrm{Mo}(\mathrm{OH})\left(\mathrm{H}_{2} \mathrm{O}\right)\right]^{+}$and $\left[\left(\mathrm{Cp}_{2} \mathrm{Mo}\right)_{2}(\mathrm{OH})_{2}\right]^{2+}$ as the main species at physiological $\mathrm{pH}$ [18], makes this system attractive for biomedical applications [19]. Another reason for excluding these compounds is that the presence of two soft $\mathrm{Cp}$ ligands renders the highest oxidation states (V and VI) less accessible [20]. There are no examples to the best of our knowledge of molybdenocenes in these oxidation states, whereas rare examples of tungsten compounds have been obtained by the oxidation of $\left[\mathrm{Cp}_{2} \mathrm{~W}\left(\mathrm{OCH}_{3}\right)\left(\mathrm{CH}_{3}\right)\right]$ with $\mathrm{Cp}_{2} \mathrm{Fe}^{+}$yielding the $\mathrm{W}^{\mathrm{V}}$ products $\left[\left(\mathrm{Cp}_{2} \mathrm{~W}\left(\mathrm{CH}_{3}\right)\right)_{2}(\mu-\mathrm{O})\right]^{2+}[21]$, which then further disproportionates in $\mathrm{MeCN}$ to yield the $\mathrm{W}^{\mathrm{VI}}$ complex $\left[\mathrm{Cp}_{2} \mathrm{~W}(\mathrm{O})\left(\mathrm{CH}_{3}\right)\right]^{+}$and solvent-trapped $\left[\mathrm{Cp}_{2} \mathrm{~W}(\mathrm{MeCN})\left(\mathrm{CH}_{3}\right)\right]^{+}[22]$. Compounds $\left[\mathrm{Cp}_{2} \mathrm{WCl}\left(\mathrm{CH}_{3}\right)\right]^{+}$and $\left[\mathrm{Cp}_{2} \mathrm{~W}\left(\eta^{2}-\mathrm{O}_{2}\right)\left(\mathrm{CH}_{3}\right)\right]^{+}$have also been described in the same report [21]. Another $\mathrm{W}^{\mathrm{VI}}$ complex, $\left[\mathrm{Cp}_{2} \mathrm{~W}(\mathrm{O})\left(\mathrm{C}_{2} \mathrm{H}_{5}\right)\right]^{+}$, was prepared by aerial oxidation of, or more conveniently by oxygen atom transfer from $\mathrm{Me}_{2} \mathrm{SO}$ or propylene oxide to, $\left[\mathrm{Cp}_{2} \mathrm{~W}\left(\mathrm{C}_{3} \mathrm{H}_{4}\right) \mathrm{H}\right]^{+}[23]$.

Another class of compounds that will be excluded from this review are those featuring alkylidenes and alkylidynes, the main members of these family being mononuclear species of type $\left[\mathrm{M}(=\mathrm{CHR})(\mathrm{NAr}) \mathrm{X}_{2}\right]$ that catalyze olefin metathesis processes (Schrock catalysts). Contrary to another family of olefin metathesis catalysts based on ruthenium (Grubbs catalysts), these compounds are typically incompatible with protic functional groups and with aqueous media. Furthermore, they have already been covered in other reviews [24-27]. We only wish to mention three trinuclear alkylidyne-capped Mo compounds, $\left[\mathrm{Mo}_{3}\left(\mathrm{CCH}_{3}\right)_{2}-\right.$ $\left.\left(\mathrm{O}_{2} \mathrm{CCH}_{3}\right)_{6}\left(\mathrm{H}_{2} \mathrm{O}\right)_{3}\right]^{\mathrm{n+}}(\mathrm{n}=1,2)[28,29]$ and $\left[\mathrm{Mo}_{3} \mathrm{O}\left(\mathrm{CCH}_{3}\right)\left(\mathrm{O}_{2} \mathrm{CCH}_{3}\right)_{6}\left(\mathrm{H}_{2} \mathrm{O}\right)_{3}\right]^{+}$[30], reported several years ago by Cotton and Bino, which are fully compatible with an aqueous 
environment. The $\left[\mathrm{Mo}_{3}\left(\mathrm{CCH}_{3}\right)_{2}\left(\mathrm{O}_{2} \mathrm{CCH}_{3}\right)_{6}\left(\mathrm{H}_{2} \mathrm{O}\right)_{3}\right]^{2+}$ complex spontaneously couples the two alkylidyne moieties in aqueous solution at room temperature to yield 2-butyne [31]. A model of the intermediate in this transformation, $\left[\mathrm{Mo}_{3} \mathrm{Br}_{7}\left(\mathrm{O}_{2} \mathrm{CCH}_{3}\right)\left(\mathrm{H}_{2} \mathrm{O}\right)_{2}\left(\mathrm{CH}_{3} \mathrm{C} \equiv \mathrm{CCH}_{3}\right)\right]$, has been isolated by carrying out the reaction in the presence of $\mathrm{HBr}$, and crystallographically characterized [31].

This article provides a general overview of molybdenum and tungsten chemistry in the highest oxidation states (mostly VI and V) with X-type hydrocarbyl ligands with respect to protic reagents and solvents. It is organized in terms of the type of hydrocarbyl ligand, first alkyls and aryls, then $\pi$-allyls, and finally cyclopentadienyls. Many of the investigations in this area, especially the most recent ones, find justification in the potential application of these materials to oxidation catalysis, particularly olefin epoxidation, although recent work has also shown potential in reductive-type processes, namely the ketone hydrosilylation [32]. These catalytic aspects have been recently reviewed and will not be covered here [33]. Other recent relevant reviews have appeared on organometallic oxides [34] and hydroxides [35] of the transition elements, as well as on dioxygen activation by organometallics of the early transition metals [36]. A concept article and a special report highlighting advances from our own group in aqueous Cp*Mo chemistry have also been published a few years ago [37, 38]. Finally, a recent review by Kühn and collaborators highlights the synthesis, reactivity and catalytic applications of mononuclear organomolybdenum(VI) dioxido complexes [39]. As such, there is a partial overlaps with this article, although the present review provides a more general coverage of high oxidation state Mo and $\mathrm{W}$ chemistry and has greater focus on chemical processes involving protic substrates and media.

\section{Alkyl and Aryl Compounds}


Beside the homoleptic compound [ $\left.\mathrm{W}\left(\mathrm{CH}_{3}\right)_{6}\right]$ already mentioned in the introduction [1], a variety of alkyl- and aryl-molybdeum(VI) and tungsten(VI) complexes have been described. The first documented examples of mixed alkyl or aryl-oxido derivatives appear to be $\left[\mathrm{MoO}_{2}(\mathrm{Mes})_{2}\right][40]$ and $\left[\mathrm{MoO}(\mathrm{Mes})_{3}\right][41]\left(\mathrm{Mes}=2,4,6-\mathrm{C}_{6} \mathrm{Me}_{3} \mathrm{H}_{2}\right)$, later followed by $\left[\mathrm{MO}\left(\mathrm{CH}_{2} t \mathrm{Bu}\right)_{3} \mathrm{Cl}\right][42],\left[\mathrm{MO}\left(\mathrm{CH}_{2} t \mathrm{Bu}\right)_{4}\right][42]$, and $\left[\mathrm{Mg}(\mathrm{THF})_{4}\right]\left[\mathrm{MO}\left(\mathrm{CH}_{3}\right)_{4}\right]_{2}[43](\mathrm{M}=\mathrm{Mo}$, W). Derivatives where the alkyl- or aryl-oxido scaffold is supported by additional Lewis bases (mostly $\mathrm{N}$-donor ligands) are also known, such as $\left[\mathrm{MO}_{2}\left(\mathrm{CH}_{3}\right)_{2} \mathrm{~L}_{2}\right]\left(\mathrm{M}=\mathrm{Mo}, \mathrm{W} ; \mathrm{L}_{2}=\mathrm{N}\right.$ based chelating ligand such as a bipyridine [44-48] or a 1,4-diazadiene [44, 49]), $\mathrm{WO}\left(\mathrm{CH}_{3}\right)_{4}$ (bipy) [46], and $\left(\mathrm{XL}_{2}\right) \mathrm{MO}_{2} \mathrm{R}\left(\mathrm{M}=\mathrm{Mo}, \mathrm{W} ; \mathrm{XL}_{2}=\kappa^{3}-\mathrm{HB}\left(3,5-\mathrm{Me}_{2} \mathrm{pz}\right)_{3}[50,51], 2-\right.$ $N$-(2-pyridylmethyl)aminophenolato [52]). Compounds containing both alkyl and cyclopentadienyl derivatives, e.g. $\mathrm{CpWO}_{2} \mathrm{R}$ and $\mathrm{CpWOR}_{3}$ [53], will be analyzed later in section 4.

In many cases, it is mentioned that the compounds are quite stable and can be handled in air, at least for short periods of time. Their thermal decomposition has been studied in detail [48], but their stability or reactivity in water has not been systematically tested. A notable exception is the alkaline hydrolysis of compounds $\left[\mathrm{MoO}_{2}(\mathrm{R}) \mathrm{Br}(\mathrm{bipy})\right](\mathrm{R}=\mathrm{Me}, \mathrm{Et}$, $\left.\mathrm{CH}_{2} t \mathrm{Bu}\right)[54,55]$. The hydrolysis occurs rapidly, but at room temperature and neutral $\mathrm{pH}$ is not accompanied by Mo-C cleavage and leads to $\left[\mathrm{RMoO}_{3}\right]^{-}$intermediates that only slowly decompose to $\left[\mathrm{MoO}_{4}\right]^{2-}$ and $\mathrm{RH}$. The X-ray structure of $\left[\mathrm{PPh}_{4}\right]\left[(\mathrm{Mes}) \mathrm{MoO}_{3}\right]$, obtained by an alternative non-aqueous route, has been reported [56]. The hydrolysis process is faster in the presence of reductants, such as $\mathrm{V}^{2+}$. The $\left[\left(t \mathrm{BuCH}_{2}\right) \mathrm{MoO}_{3}\right]^{-}$anion decays with $\mathrm{t}_{1 / 2}=$ ca. 15 days at $23^{\circ} \mathrm{C}$ and $282 \mathrm{~min}$ at $70^{\circ} \mathrm{C}$ at $\mathrm{pH} 11$ [55].

Compounds $\left[\mathrm{MoO}_{2} \mathrm{R}_{2}\right.$ (bipy)] $\left(\mathrm{R}=\mathrm{Me}, \mathrm{CH}_{2} t \mathrm{Bu}\right)$ are quite resistant to hydrolysis, a fact that is attributed to their hydrophobic nature. Quantitative yields of methane or neopentane, respectively, requires fusion with $\mathrm{KOH}$, while only $13 \%$ and $0.2 \%$ decomposition occurs upon heating in glycerol at $90^{\circ} \mathrm{C}$ for $1 \mathrm{~h}$. Their half life is reduced to $30 \mathrm{~min}$ in glacial acetic acid at $90^{\circ} \mathrm{C}$ and to $5 \mathrm{~min}$ in concentrated $\mathrm{H}_{2} \mathrm{SO}_{4}$ at room temperature. However, the Mo-C 
bonds become more sensitive to cleavage upon reduction [57]. The hydrolysis of one member of the $\mathrm{Tp}^{*} \mathrm{MO}_{2} \mathrm{R}$ family, specifically $\mathrm{Tp} * \mathrm{WO}_{2}\left(\mathrm{CHPPh}_{3}\right)$, was reported to occur readily, leading to evolution of methane and formation of $\left[\mathrm{Ph}_{3} \mathrm{POH}\right]\left[\mathrm{Tp}^{*} \mathrm{WO}_{3}\right][50]$.

Most synthetic efforts in high oxidation state alkylmolybdenum and tungsten chemistry have been carried out in search for better catalysts for the olefin epoxidation reaction. High oxidation state oxidomolybdenum and tungsten species are commonly used in this reaction, with the preferred oxygen transfer agents being the protic substances tert-butylhydroperoxide (TBHP). Most reactions are investigated in apolar solvents, but the use of aqueous media is gaining interest [58]. Dialkyl compounds of type $\mathrm{MoO}_{2} \mathrm{R}_{2} \mathrm{~L}_{2}\left(\mathrm{R}=\mathrm{Me}, \mathrm{Et} ; \mathrm{L}_{2}=\right.$ substituted diazadiene or bipyridine) were found to be active catalysts when using TBHP, but inactive when using $\mathrm{H}_{2} \mathrm{O}_{2}$ [39]. A spectroscopic study of the interaction between $\left[\mathrm{MoO}_{2}\left(\mathrm{CH}_{3}\right)_{2} \mathrm{~L}_{2}\right]\left(\mathrm{L}_{2}\right.$ $=4,4^{\prime}$-dihexyl-2,2'-bipyridine) and TBHP, of relevance to catalytic cycle, suggests that the TBHP hydrogen atom is transferred to one of the terminal oxido ligands, rather than leading to $\mathrm{CH}_{4}$ elimination or protonation of the Lewis base ligand, see Scheme 2 [59].

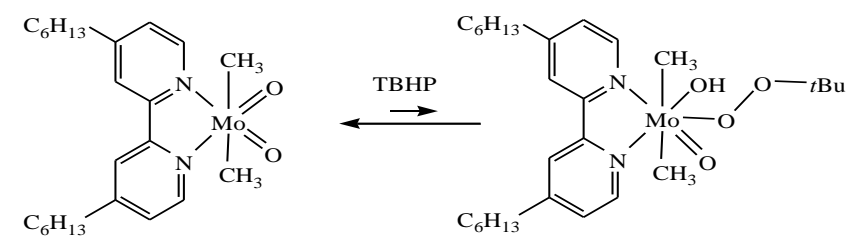

Scheme 2

\section{3. $\pi$-Allyl Compounds}

The chemistry of allylmolybdenum and allyltungsten derivatives in high oxidation states has been very little developed. A rare example of an allyl derivative is Tp* $\mathrm{WO}_{2}\left(\mathrm{CH}_{2} \mathrm{CMe}=\mathrm{CH}_{2}\right)$ [60], but since the allyl ligand is only $\sigma$-bonded to the transition metal, this compound qualifies as a simple alkyl complex. Related $\pi$-bonded complexes might 
be accessible by replacing Tp* with a bidentate (XL-type) ligand. A $\pi$-allyl oxido tungsten derivative has been proposed as an intermediate in an allyl alcohol deoxygenation process induced by compound $\left[\mathrm{WCl}_{4}\left(\mathrm{PMe}_{3}\right)_{2}\right][61,62]$ and a chloride derivative, $\left[\mathrm{WO}\left(\eta^{3}-\right.\right.$ $\left.\mathrm{C}_{3} \mathrm{H}_{5}\right) \mathrm{Cl}\left(\mathrm{PMe}_{3}\right)_{2}$ ] has been isolated and structurally characterized [63]. The behaviour of these compounds in water or in the presence of protic reagents does not appear to have been explored. A number of carbonyl-based allyl derivatives containing also hydroxido or aqua ligands are known in lower oxidation states [64-66], but oxidative processes leading to higher oxidation state derivatives have not so far been reported.

\section{Cyclopentadienyl Compounds}

Complexes containing "open" pentadienyl ligands have received a certain degree of attention for early transition metals [67], but no such compounds have been described to date for molybdenum and tungsten, to the best of our knowledge. On the other hand, investigations of derivatives with the ubiquitous cyclopentadienyl ligand, especially the fully methyl-substituted version $\left(\mathrm{Cp}^{*}\right)$, have been extensive.

\subsection{Synthetic aspects}

Two basic approaches have mainly been used: (1) the direct oxidation of suitable lowvalent (typically carbonyl) precursors; (2) hydrolysis processes from easily accessible highvalent precursors.

\section{Oxido and mixed halido-oxido derivatives}

Most early synthetic efforts leading to high oxidation state organomolybdenum and tungsten derivatives have been restricted to anhydrous conditions and non protic reagents, e.g. 
the oxidation of low-valent carbonyl precursors with $\mathrm{O}_{2}$, or the replacement of a Mo-Cl bond with a $\mathrm{Cp}^{-}$delivering agent. However, wet routes have also been developed relatively early and have recently found to be quite convenient, especially for the substituted ring systems.

The systems containing the unsubstituted Cp ligand were the first ones to be described. Early anhydrous oxidation routes involve thermal or photochemical reactions with $\mathrm{O}_{2}$, whereby $\left[\mathrm{Cp}_{2} \mathrm{Mo}_{2}(\mathrm{CO})_{6}\right]$ in chloroform leads to mixtures of $\left[\mathrm{Cp}_{2} \mathrm{Mo}_{2} \mathrm{O}_{4}\right],\left[\mathrm{CpMoO}_{2} \mathrm{Cl}\right]$ and $\left[\mathrm{Cp}_{2} \mathrm{Mo}_{2} \mathrm{O}_{5}\right][68]$ and $\left[\mathrm{CpMo}\left(\eta^{6}-\mathrm{C}_{6} \mathrm{H}_{6}\right) \mathrm{Cl}\right]^{+}$or $\left[\mathrm{CpMo}(\mathrm{NO})_{2} \mathrm{Cl}\right]$ more selectively afford $\left[\mathrm{CpMoO}_{2} \mathrm{Cl}\right][69,70]$. Examples of $\mathrm{Cp} / \mathrm{Cl}$ exchange processes are the synthesis of $\left[\mathrm{CpMoOCl}_{2}\right]$ from $\left[\mathrm{MoOCl}_{3}\right]$ and $\mathrm{CpSnBu}_{3}[71,72]$ and that of $\left[\mathrm{CpMoO}_{2} \mathrm{Cl}\right]$ from $\left[\mathrm{MoO}_{2} \mathrm{Cl}_{2}(\mathrm{dme})\right]$ and $\mathrm{CpTl}$ [73]. As early as 1964, however, it was noted that the hydrolysis of $\left[\mathrm{CpMoCl}_{4}\right]$ leads to $\left[\mathrm{CpMoOCl}_{2}\right]$ by spontaneous decomposition in moist air [68], and to red tetranuclear $\left[\mathrm{CpMoO}_{2}\right]_{4}$ (I) by treatment with excess $\mathrm{H}_{2} \mathrm{O}$ [9]. The latter compound is unstable and isomerizes to orange dinuclear $\left[\mathrm{Cp}_{2} \mathrm{Mo}_{2} \mathrm{O}_{4}\right]$, the structure of which has been determined [74]. The precise structure of intermediate $\mathbf{I}$, on the other hand, is still unknown. An analogous hydrolytic behaviour was also observed for the tetrabromido derivative, [CpMoBr 4 ] [9], as well as for $\eta^{5}-\mathrm{C}_{5} \mathrm{H}_{4} \mathrm{R}$ derivatives $(\mathrm{R}=\mathrm{Me}, i \mathrm{Pr}, t \mathrm{Bu})$ [71], see Scheme 3. Since compound $\left[\mathrm{CpMoCl}_{4}\right]$ has later become more readily available in high yields by oxidation of $\left[\mathrm{Cp}_{2} \mathrm{Mo}_{2}(\mathrm{CO})_{6}\right]$ or $\left[\mathrm{CpMo}(\mathrm{CO})_{3}\left(\mathrm{CH}_{3}\right)\right]$ and $\mathrm{PCl}_{5}$ or $\mathrm{PhICl}_{2}$ [75-77], the hydrolytic synthesis of the oxido derivatives has been further optimized [78]. The procedure is in fact a convenient entry to the $\mathrm{Mo}^{\mathrm{VI}}$ derivative $\left[\mathrm{Cp}_{2} \mathrm{Mo}_{2} \mathrm{O}_{5}\right]$, which is obtained by further oxidation of the $\mathrm{CpMo}^{\mathrm{V}}$ oxido products. While orange dinuclear $\left[\mathrm{Cp}_{2} \mathrm{Mo}_{2} \mathrm{O}_{4}\right]$ is only oxidized with difficulty [71] (probably because of the presence of a strong Mo-Mo bond), the red tetranuclear intermediate is rapidly oxidized by $\mathrm{PhIO}$ [78].

Compound $\left[\mathrm{Cp}_{2} \mathrm{Mo}_{2} \mathrm{O}_{5}\right]$ is not indefinitely stable in water [79]. On the other hand, the $\mathrm{Cp}^{*}$ analogue appears to resist hydrolytic decomposition in water in the entire $\mathrm{pH}$ range (more details in section 4.2) [80], although a very slow decomposition occurs under extreme 
acidic conditions as shown in section 4.4. This is the main reason for which greater effort has been dedicated to the study of the aqueous chemistry of the $\mathrm{Cp} *$ Mo and W system.

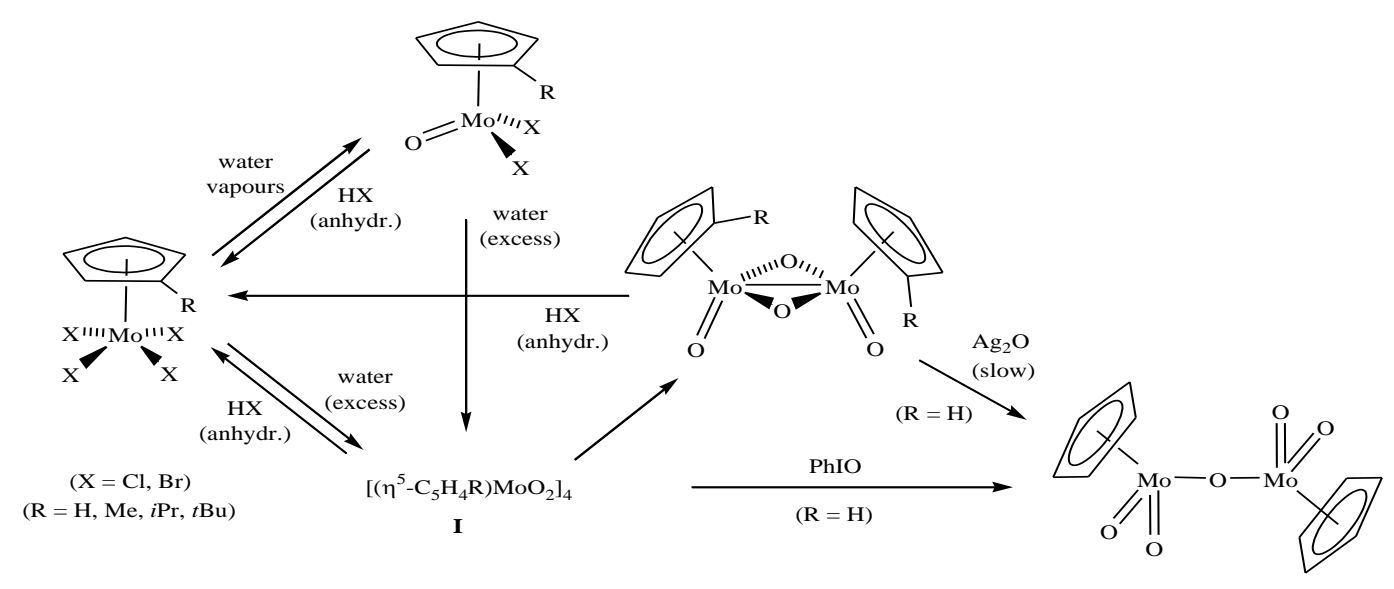

Scheme 3

High oxidation state compounds containing substituted cyclopentadienyl rings have also been obtained initially by anhydrous oxidative procedures. Compounds $\left[\mathrm{Cp}^{*}{ }_{2} \mathrm{Mo}_{2} \mathrm{O}_{5}\right]$ and $\left[\mathrm{Cp}_{2}{ }_{2} \mathrm{~W}_{2} \mathrm{O}_{5}\right]$ have first been obtained from compounds $\mathrm{Cp} * \mathrm{Mo}(\mathrm{CO})_{2}(\mathrm{NO})$ [10], $\left[\mathrm{Cp} * \mathrm{M}(\mathrm{CO})_{2}\right]_{2} \quad(\mathrm{M}=\mathrm{Mo}, \quad \mathrm{W}) \quad[81, \quad 82], \quad\left[\mathrm{Cp} * \mathrm{Mo}(\mathrm{CO})_{2}(\mathrm{OMe})\right]_{\mathrm{n}} \quad[83], \quad$ and $\left[\mathrm{Cp}^{*} \mathrm{MoBr}\left(\mathrm{CH}_{3}\right)(\mathrm{NO})\right]_{2}[84]$ in the presence of $\mathrm{O}_{2}$. When the irradiation of $\left[\mathrm{Cp}^{*} \mathrm{Mo}(\mathrm{CO})_{2}\right]_{2}$ was carried out in $\mathrm{CH}_{2} \mathrm{Cl}_{2}$ with a restricted supply of $\mathrm{O}_{2}$, a mixture of compounds $\left[(\mathrm{Cp} * \mathrm{MoCl})_{2}(\mu-\mathrm{Cl})_{2}(\mu-\mathrm{O})\right]$ and $\left[(\mathrm{Cp} * \mathrm{MoCl})_{2}(\mu-\mathrm{Cl})\left(\mu-\mathrm{CO}_{3} \mathrm{H}\right)(\mu-\mathrm{O})\right]$ was obtained instead [85]. Analogously, $\left[\mathrm{Cp} * \mathrm{MoO}_{2} \mathrm{Cl}\right]$ was obtained from $\left[\mathrm{Cp} * \mathrm{Mo}(\mathrm{CO}){ }_{3} \mathrm{Cl}\right][86]$ and $\left[\left(\mathrm{C}_{5} \mathrm{Ph}_{4}(2,5-\right.\right.$ $\left.\left.\mathrm{C}_{6} \mathrm{H}_{3}(\mathrm{OMe})_{2}\right)\right) \mathrm{MoO}_{2} \mathrm{Br}$ ] from $\left[\left(\mathrm{C}_{5} \mathrm{Ph}_{4}\left(2,5-\mathrm{C}_{6} \mathrm{H}_{3}(\mathrm{OMe})_{2}\right)\right) \mathrm{Mo}(\mathrm{CO})_{3} \mathrm{Br}\right.$ ] [87]. The oxidation strategy has recently been made more convenient and general by the use of TBHP in place of $\mathrm{O}_{2}$, leading to the preparation of $\left[\left(\mathrm{C}_{5} \mathrm{H}_{4} \mathrm{R}\right) \mathrm{MoO}_{2} \mathrm{Cl}\right]$ from $\left[\left(\mathrm{C}_{5} \mathrm{H}_{4} \mathrm{R}\right) \mathrm{Mo}(\mathrm{CO})_{3} \mathrm{Cl}\right](\mathrm{R}=\mathrm{H}, \mathrm{Me}$, $\mathrm{Bz}$ ) [88]. The reactions are fast at room temperature and high-yielding. The protic reagent (the acidity of TBHP is greater than that of water) does not appear to perturb the cyclopentadienyl-metal interaction. This protocol is also effective when using higheroxidation state starting materials, e.g. compound $\left[\left(\mathrm{C}_{5} \mathrm{Bzz}_{5}\right) \mathrm{MoO}_{2} \mathrm{Cl}\right]$ is obtained from 
$\left[\left(\mathrm{C}_{5} \mathrm{Bz}_{5}\right) \mathrm{MoCl}_{3}(\mathrm{COMe})\right]$ (the reaction takes place with the intermediate formation of $\left.\left[\left(\mathrm{C}_{5} \mathrm{Bz}_{5}\right) \mathrm{MoOCl}_{2}\right]\right)$ and $\left[\left(\mathrm{C}_{5} \mathrm{Bz}_{5}\right) \mathrm{WO}_{2} \mathrm{Cl}\right]$ from $\left[\left(\mathrm{C}_{5} \mathrm{Bz}_{5}\right) \mathrm{WCl}_{4}\right][89]$.

The first reported wet route involved the treatment of $\left[\mathrm{Cp}^{*} \mathrm{MoCl}_{4}\right]$ with either $\mathrm{Na}_{2} \mathrm{MoO}_{4}, \mathrm{Na}_{2} \mathrm{WO}_{4}$, or $\mathrm{NaVO}_{3}$ in water, yielding $\left[\mathrm{Cp}_{2}{ }_{2} \mathrm{Mo}_{2} \mathrm{O}_{5}\right]$ after acidification with $\mathrm{HCl}$ [90], whereas the simple addition of water without inorganic oxidants gave poorly characterized materials, and the same reaction carried out in THF led to a $\mathrm{Mo}^{\mathrm{V}}$ product, $\left[\mathrm{Cp}_{2}{ }_{2} \mathrm{Mo}_{2} \mathrm{O}_{3} \mathrm{Cl}_{2}\right]$. A subsequent study revealed that the basic $(\mathrm{NaOH})$ hydrolysis of $\left[\mathrm{Cp}^{*} \mathrm{MoCl}_{4}\right]$ in the absence of air yields $\left[\mathrm{Cp} * \mathrm{MoOCl}_{2}\right]$, whereas the same procedure in air yields $\left[\mathrm{Cp} * \mathrm{MoO}_{2} \mathrm{Cl}\right]$ or $\left[\mathrm{Cp}^{*}{ }_{2} \mathrm{Mo}_{2} \mathrm{O}_{5}\right]$, depending on the amount of base used [91]. In the case of tungsten, aerial oxidation also leads to the chloridodioxido product, [Cp* $\left.\mathrm{WO}_{2} \mathrm{Cl}\right]$, whereas in the absence of air the reaction allows the identification of two intermediates, formulated as $\left[\mathrm{Cp}^{*} \mathrm{WCl}_{3}(\mathrm{OH})\right]$ and $\left[\mathrm{Cp}^{*} \mathrm{WCl}_{2}(\mathrm{OH})_{2}\right]$ on the basis of spectroscopic evidence [91]. The alternative hydrolysis using $t \mathrm{BuNH}_{2}$ yields $\left[t \mathrm{BuNH}_{3}\right]\left[\mathrm{Cp} * \mathrm{MoO}_{3}\right]$, from which $\left[\mathrm{Cp}_{2}{ }_{2} \mathrm{Mo}_{2} \mathrm{O}_{5}\right]$ may be recovered by acidification (the tungsten analogue was similarly prepared via the $\left[t \mathrm{BuNH}_{3}\right]\left[\mathrm{Cp} * \mathrm{WO}_{3}\right]$ intermediates) [91]. Compound $\left[\mathrm{Cp} * \mathrm{MoO}_{2} \mathrm{Cl}\right]$ was also shown to be conveniently prepared $(86 \%$ yield $)$ by a wet oxidative route, from $\left[\mathrm{Cp}_{2}{ }_{2} \mathrm{Mo}_{2}(\mathrm{CO})_{4}\right]$ and excess (> 10:1) $30 \%$ aqueous $\mathrm{H}_{2} \mathrm{O}_{2}$ in chloroform which was further acidified with $\mathrm{HCl}$ [92]. Interestingly, this procedure does not yield the peroxido derivative $\left[\mathrm{Cp} * \mathrm{MoO}\left(\mathrm{O}_{2}\right) \mathrm{Cl}\right]$, which is easily formed from $\left[\mathrm{Cp}^{*} \mathrm{MoO}_{2} \mathrm{Cl}\right]$ and TBHP in organic media (vide infra). It is possible that the peroxido product is unstable in the strongly acidic medium, although this has not been tested to the best of our knowledge. The hydrolysis of $\left[(\mathrm{Cp} * \mathrm{MoOCl})_{2}(\mu-\mathrm{O})\right]$ in the presence of $\mathrm{NEt}_{3}$ gives a high yield of $[\mathrm{Cp} * \mathrm{MoO}(\mu-\mathrm{O})]_{2}[92]$.

Later, the synthesis of $\left[\mathrm{Cp}^{*}{ }_{2} \mathrm{Mo}_{2} \mathrm{O}_{5}\right]$ was further optimized and extended to the preparation of compounds [Cp' $\left.{ }_{2} \mathrm{Mo}_{2} \mathrm{O}_{5}\right]$ with $\mathrm{Cp}^{\prime}=\mathrm{C}_{5} \mathrm{H} i \mathrm{Pr}_{4}$ and $1,2,4-\mathrm{C}_{5} \mathrm{H}_{2} t \mathrm{Bu}_{3}$ [78]. It was found that the anaerobic hydrolysis of $\left[\mathrm{Cp}^{*} \mathrm{MoCl}_{4}\right]$ ultimately leads to $\left[\mathrm{Cp}^{*}{ }_{2} \mathrm{Mo}_{2} \mathrm{O}_{4}\right]$ in the presence of excess $\mathrm{NaOH}$, whereas the sodium salt, $\mathrm{Na}\left[\mathrm{Cp}^{*} \mathrm{MoO}_{3}\right]$, is obtained in the 
presence of air and excess $\mathrm{NaOH}$, see Scheme 4. Since the dinuclear $\mathrm{Mo}^{\mathrm{V}}$ compound is more resistant than $\left[\mathrm{Cp}^{*} \mathrm{MoOCl}_{2}\right]$ to aerial oxidation, the aerobic hydrolysis of $\left[\mathrm{Cp}^{*} \mathrm{MoCl}_{4}\right]$ in the presence of excess base always leads to mixtures of $\mathrm{Na}\left[\mathrm{Cp} * \mathrm{MoO}_{3}\right]$ and $\left[\mathrm{Cp}^{*}{ }_{2} \mathrm{Mo}_{2} \mathrm{O}_{4}\right]$, lowering the final $\left[\mathrm{Cp}^{*}{ }_{2} \mathrm{Mo}_{2} \mathrm{O}_{5}\right]$ yield after acidification. Formation of the $\mathrm{Mo}^{\mathrm{V}}$ by-product is minimized by first carrying out the aerial hydrolysis with only 2 equivalents of $\mathrm{NaOH}$, and then completing the hydrolysis with additional base after most of the material has been converted to $\left[\mathrm{Cp}^{*} \mathrm{MoO}_{2} \mathrm{Cl}\right]$. An alternative hydrolytic approach involves protonolysis of $\left[\mathrm{Cp} * \mathrm{M}(\mathrm{N} t \mathrm{Bu})_{2} \mathrm{Cl}\right](\mathrm{M}=\mathrm{Mo}, \mathrm{W})$ with aqueous $\mathrm{HCl}$ [93]. The starting materials used for this approach were obtained from $\mathrm{Mo}(\mathrm{N} t \mathrm{Bu})_{2} \mathrm{Cl}_{2}$ or $\mathrm{W}(\mathrm{N} t \mathrm{Bu})_{2} \mathrm{Cl}_{2}(\mathrm{py})_{2}$ and $\mathrm{Cp} * \mathrm{Li}$.

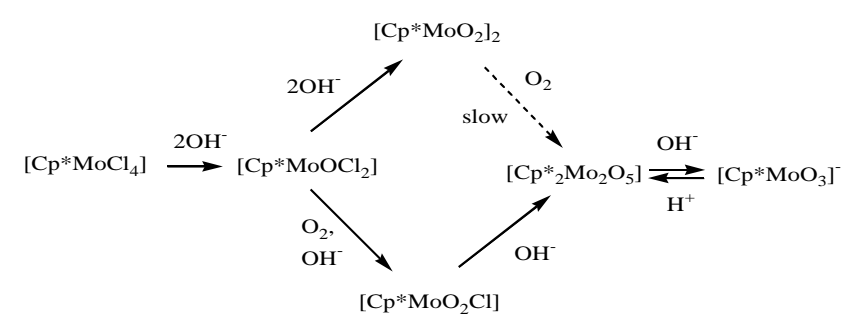

Scheme 4

Although the yields of the above synthetic procedures starting from $\left[\mathrm{Cp} * \mathrm{MCl}_{4}\right]$ or $\left[\mathrm{Cp} * \mathrm{M}(\mathrm{N} t \mathrm{Bu})_{2} \mathrm{Cl}\right]$ are good to excellent, they require the preliminary and sometime lengthy preparation of the starting materials from commercially available products. For instance, the synthesis of $\left[\mathrm{Cp}^{*} \mathrm{MCl}_{4}\right]$ requires three steps from $\left[\mathrm{M}(\mathrm{CO})_{6}\right][94,95]$, requiring isolation of the $\mathrm{Cp} * \mathrm{M}(\mathrm{CO})_{3}\left(\mathrm{CH}_{3}\right)$ intermediate. The full synthesis from $\left[\mathrm{M}(\mathrm{CO})_{6}\right]$ is shown in Scheme 5Erreur ! Source du renvoi introuvable.. A short-cut consisting of a three-step, one-pot procedure has recently been reported [96]. This involves the direct oxidation of $\mathrm{Na}\left[\mathrm{Cp} * \mathrm{M}(\mathrm{CO})_{3}\right]$, formed in a first step from $\left[\mathrm{M}(\mathrm{CO})_{6}\right]$ and $\mathrm{NaCp}^{*}$, with $t \mathrm{BuOOH}$ in water [96]. It saves two steps with respect to the procedure of ref. [78]Erreur ! Source du renvoi introuvable., it does not require the isolation of any intermediate, and it gives high yields for 
both $\mathrm{Mo}(91 \%)$ and $\mathrm{W}(87 \%)$. The alternative use of $\mathrm{H}_{2} \mathrm{O}_{2}$ as oxidizing agent also leads to the desired product, but in lower and less reproducible yields.

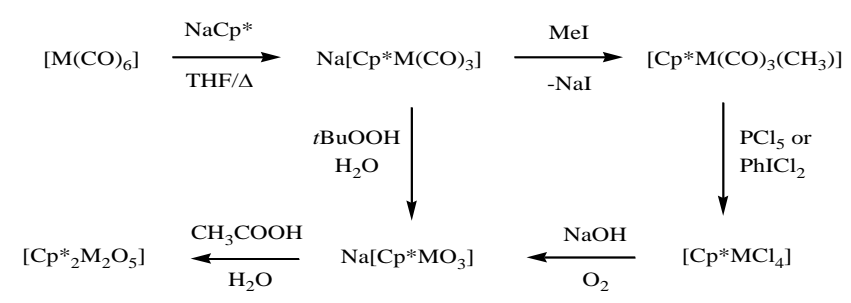

\section{Scheme 5}

This synthesis, which underscores the robustness of the $\mathrm{Cp}^{*}-\mathrm{M}$ bond in high and low oxidation states in the presence of water, was inspired by earlier reports of the direct oxidation of low-valent carbonyl derivatives by TBHP or $\mathrm{H}_{2} \mathrm{O}_{2}$ to afford $\mathrm{Mo}^{\mathrm{VI}}$ dioxido products in high yields, e.g. $\left[\mathrm{Cp} * \mathrm{MoO}_{2} \mathrm{Cl}\right]$ from $\left[\mathrm{Cp} * \mathrm{Mo}(\mathrm{CO})_{\mathrm{n}}\right]_{2}$ (mixture with $n=2$ and 3) [92, 97] or $\left[\mathrm{Cp} * \mathrm{Mo}(\mathrm{CO})_{3} \mathrm{Cl}\right][88]$ and $\left[\mathrm{Cp}^{*} \mathrm{MoO}_{2}\left(\mathrm{CH}_{3}\right)\right]$ from $\left[\mathrm{Cp} * \mathrm{Mo}(\mathrm{CO})_{3}\left(\mathrm{CH}_{3}\right)\right]$ [98], although some of these had only been described in anhydrous solvents.

\section{Alkyl-and aryl-derivatives with and without oxido ligands.}

The only two examples of monocyclopentadienyl derivatives of Mo and W containing only alkyls as additional ligands appear to be $\left[\mathrm{Cp}^{*} \mathrm{M}\left(\mathrm{CH}_{3}\right)_{4}\right](\mathrm{M}=\mathrm{Mo}, \mathrm{W})$, and the oneelectron oxidation product of the latter, $\left[\mathrm{Cp} * \mathrm{~W}\left(\mathrm{CH}_{3}\right)_{4}\right]^{+}[99]$. The $\mathrm{M}^{\mathrm{V}}$ compounds were obtained by direct alkylation of $\left[\mathrm{Cp}^{*} \mathrm{MoCl}_{4}\right]$ with $\mathrm{MeMgCl}[100]$ and $\left[\mathrm{Cp} * \mathrm{WCl}_{4}\left(\mathrm{PMe}_{3}\right)\right]$ with $\mathrm{ZnMe}_{2}$ [94]. In several instances, M-X bonds have been cleanly alkylated to yield the corresponding $\mathrm{M}-\mathrm{R}$ bonds without affecting any $\mathrm{M}=\mathrm{O}$ or other bonds present. Thus, $\left[\mathrm{Cp}^{*} \mathrm{WO}_{2} \mathrm{Cl}\right]$ reacts with $\mathrm{RMgCl}$ to afford $\left[\mathrm{Cp}^{*} \mathrm{WO}_{2} \mathrm{R}\right]\left(\mathrm{R}=\mathrm{CH}_{3}, \mathrm{CH}_{2} \mathrm{SiMe}_{3}\right)$, although the $\mathrm{MeMgCl}$ reagent yields $\left[\mathrm{Cp}^{*} \mathrm{WO}\left(\mathrm{CH}_{3}\right)_{3}\right]$ as the major product $[101,102]$. However, analogous alkylations do not work for the related $\mathrm{Mo}^{\mathrm{VI}}-\mathrm{Cl}$ compounds [81]. Compounds $\left[\mathrm{Cp} * \mathrm{M}(\mathrm{N} t \mathrm{Bu})_{2} \mathrm{Cl}\right]$ have been alkylated to $\left[\mathrm{Cp} * \mathrm{M}(\mathrm{N} t \mathrm{Bu})_{2}\left(\mathrm{CH}_{3}\right)\right]$ for both Mo and $\mathrm{W}$ [93]. 
Aerial oxidation of [Cp'M(NO)R $\left.\mathrm{R}_{2}\right]\left(\mathrm{Cp}^{\prime}=\mathrm{Cp}, \mathrm{Cp}^{*} ; \mathrm{M}=\mathrm{Mo}, \mathrm{W} ; \mathrm{R}=\mathrm{CH}_{3}, \mathrm{CH}_{2} \mathrm{SiMe}_{3}\right)$ is a more convenient entry into many dioxide $\mathrm{M}^{\mathrm{VI}}$ derivatives $\left[\mathrm{Cp}^{\prime} \mathrm{MO}_{2} \mathrm{R}\right][53,70,103]$. A remarkable feature of this reaction is that higher yields are obtained when water is present [103]. When the above compounds $\left[\mathrm{Cp}^{\prime} \mathrm{M}(\mathrm{NO}) \mathrm{R}_{2}\right]$ (for $\mathrm{M}=\mathrm{Mo}$ ) are treated with small amounts of water in the absence of $\mathrm{O}_{2}$, they convert to another family of compounds, $\left[\left(\mathrm{Cp}^{\prime} \mathrm{Mo}(\mathrm{NO}) \mathrm{R}\right)_{2}(\mu-\mathrm{O})\right]$, whereas excess water leads to $\left[\mathrm{Cp}_{2}{ }_{2} \mathrm{Mo}_{2} \mathrm{O}_{5}\right][104]$. In marked contrast, the tungsten analogues are perfectly stable in the presence of water for $\mathrm{R}=$ alkyl, but react instantaneously to yield once again $\left[\mathrm{Cp}^{\prime} \mathrm{WO}_{2} \mathrm{R}\right]$ for $\mathrm{R}=$ aryl $(\mathrm{Ph}, o$-Tol, $p$-Tol) $[104$, 105]. Within this group of reactions, that of the specific $\left[\mathrm{CpW}(\mathrm{NO})(o-\mathrm{Tol})_{2}\right]$ compound stands out because, in addition to the dioxide product, it also gives the product of a remarkable water induced isomerization, [Cp'WO(NR)R], see Scheme 6. Use of $\mathrm{H}_{2}{ }^{18} \mathrm{O}$ with the $\left[\mathrm{CpW}(\mathrm{NO})(o-\mathrm{Tol})_{2}\right]$ complex showed that the isomerization process is intramolecular (there is no ${ }^{18} \mathrm{O}$ incorporation in the intermediate) and no reagent other than $\mathrm{H}_{2} \mathrm{O}$ was found to induce this isomerization process. For instance, $i \mathrm{PrOH}$ and $t \mathrm{BuNH}_{2}$ gave instead products or $\mathrm{W}-(p-\mathrm{Tol})$ bond protonolysis, $[\mathrm{CpW}(\mathrm{NO})(o-\mathrm{Tol})(\mathrm{O} i \mathrm{Pr})]$ and $[\mathrm{CpW}(\mathrm{NO})(o-\mathrm{Tol})(\mathrm{NH} t \mathrm{Bu})]$ [106]. On the basis of the established hydrolysis of $\mathrm{M}^{\mathrm{VI}}$ (imido) functions (see section 4.4), it seems possible that the dioxido product originates from the mixed oxido-imido product by further hydrolysis, but this does not seem to be established. The reason for the observation of the oxido-imido intermediate only in this specific case could be related to the steric hydrance of the $p$-Tol group, slowing down the subsequent hydrolysis step.

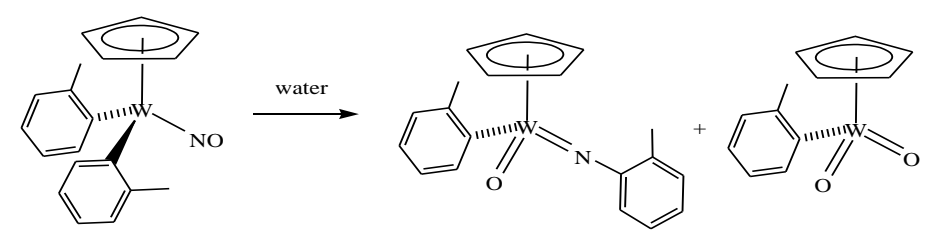

\section{Scheme 6}


The same oxidation process occurs more rapidly when the $\left[\mathrm{Cp}^{\prime} \mathrm{M}(\mathrm{NO}) \mathrm{R}_{2}\right]$ precursors are treated with $\mathrm{H}_{2} \mathrm{O}_{2}$ [107], although the stoichiometry of the oxidizing agent must be carefully controlled to avoid further conversion. In fact, these alkyl derivatives react rather easily with excess $\mathrm{H}_{2} \mathrm{O}_{2}$ or other hydroperoxide reagents to yield the corresponding peroxido derivatives (see section 4.4) [101, 103, 107].

More recently, it has been shown that dioxidoalkyl compounds may be obtained by oxidation of readily accessible tricarbonyl alkyl derivatives with TBHP or $\mathrm{H}_{2} \mathrm{O}_{2}$. However, the reaction easily proceeds further to the peroxide complex, even when the stoichiometric amount of oxidant is used. Thus, it is best to convert [Cp'M(CO) $\left.{ }_{3} \mathrm{R}\right]$ directly to [Cp'MO( $\left.\left(\mathrm{O}_{2}\right) \mathrm{R}\right]$ and then reduce the peroxide function to oxido by treatment with an oxygen atom acceptor such as $\mathrm{PPh}_{3}$. Using this strategy, the acetylide complexes $\left[\mathrm{Cp} * \mathrm{WO}\left(\mathrm{O}_{2}\right)(\mathrm{C} \equiv \mathrm{CR})\right]\left(\mathrm{R}=\mathrm{Ph}, \mathrm{CH}_{2} \mathrm{OMe}, n \mathrm{Pr}\right.$ and $\left.\mathrm{C}(\mathrm{Me})=\mathrm{CH}_{2}\right)$ were obtained in good yields from the corresponding $\left[\mathrm{Cp} * \mathrm{~W}(\mathrm{CO})_{3}(\mathrm{C} \equiv \mathrm{CR})\right]$ and acidic solutions of $\mathrm{H}_{2} \mathrm{O}_{2}$ at room temperature and then converted to $\left[\mathrm{Cp} * \mathrm{WO}_{2}(\mathrm{C} \equiv \mathrm{CR})\right][108]$. The same strategy gives $\left[\mathrm{Cp}^{*} \mathrm{WO}_{2}(\mathrm{C} \equiv \mathrm{C}-\mathrm{C} \equiv \mathrm{CH})\right] \quad$ from $\quad\left[\mathrm{Cp} * \mathrm{~W}(\mathrm{CO})_{3}(\mathrm{C} \equiv \mathrm{C}-\mathrm{C} \equiv \mathrm{CH})\right] \quad$ and $\quad\left[\mathrm{Cp}^{*} \mathrm{O}_{2} \mathrm{~W}-\mathrm{C} \equiv \mathrm{C}-\mathrm{C} \equiv \mathrm{C}-\right.$ $\left.\mathrm{WO}_{2} \mathrm{Cp} *\right]$ from $\left[\mathrm{Cp} *(\mathrm{CO})_{3} \mathrm{~W}-\mathrm{C} \equiv \mathrm{C}-\mathrm{C} \equiv \mathrm{C}-\mathrm{W}(\mathrm{CO})_{3} \mathrm{Cp}^{*}\right]$ via the corresponding peroxide complexes [109]. Analogously, $\left[\mathrm{CpMoO}_{2}\left(\mathrm{CH}_{3}\right)\right]$ was obtained from $\left[\mathrm{CpMo}(\mathrm{CO})_{3}\left(\mathrm{CH}_{3}\right)\right]$ and TBHP [98]. Since these dioxido alkyl complexes have been shown to efficiently catalyze the olefin epoxidation reaction, which requires TBHP as a stoichiometric oxidant, the more easily accessible tricarbonyl derivatives can be used as pre-catalysts, generating the active dioxido complexes in situ $[98,110,111]$.

\section{Oxido-phosphine complexes}

A particular type of phosphine-containing cyclopentadienyl oxido derivatives of molybdenum have been obtained by treatment of hydride complexes with water. By analogy 
with the $\mathrm{Cp}_{2} \mathrm{Mo}^{2+}$ system, the presence of soft phosphine donor ligands destabilizes the highest oxidation states, these derivatives existing only in oxidation states up to IV.

Thus, complexes $[\mathrm{CpMoO}(\mathrm{dmpe})]^{+}$and $\left[\mathrm{CpMoO}\left(\mathrm{PMe}_{3}\right)_{2}\right]^{+}$have been obtained from the $\left[\mathrm{CpMo}(\mathrm{dmpe}) \mathrm{H}_{4}\right]^{+}[112]$ and $\left[\mathrm{CpMo}\left(\mathrm{PMe}_{3}\right)_{3} \mathrm{H}\right]^{+}[113]$ precursors upon reaction with water. In the latter case, DFT studies and the isolation of intermediates indicates a complex mechanism involving water-induced disproportionation of the paramagnetic (17-electron, formally $\left.\mathrm{Mo}^{\mathrm{III}}\right)$ hydride to give $\left[\mathrm{CpMo}\left(\mathrm{PMe}_{3}\right)_{3}\left(\mathrm{H}_{2} \mathrm{O}\right) \mathrm{H}\right]^{2+}$, followed by double deprotonation to $\left[\mathrm{CpMo}\left(\mathrm{PMe}_{3}\right)_{3}(\mathrm{OH})\right]$ (which is in equilibrium with isolated $\left[\mathrm{CpMo}\left(\mathrm{PMe}_{3}\right)_{2}(\mathrm{OH})\right]$ and free $\mathrm{PMe}_{3}$ ), subsequent oxidation to $\left[\mathrm{CpMo}\left(\mathrm{PMe}_{3}\right)_{3}(\mathrm{OH})\right]^{+}$(which was isolated and structurally characterized [114]), and further oxidation, deprotonation and $\mathrm{PMe}_{3}$ decoordination to complete the process [113]. Oxidation of compounds $\left[\left(\mathrm{C}_{5} \mathrm{R}_{5}\right) \mathrm{Mo}(\mathrm{dppe}) \mathrm{H}_{3}\right](\mathrm{R}=\mathrm{Me}, \mathrm{Et})$ in the presence of water, on the other hand, yields the neutral bis(hydroxido) derivatives $\left[\left(\mathrm{C}_{5} \mathrm{R}_{5}\right) \mathrm{Mo}(\mathrm{dppe})(\mathrm{OH})_{2}\right]$ [115], the structure of which was confirmed by X-ray diffraction for $\mathrm{R}=\mathrm{Et}$.

An analogous system containing a phosphine-functionalized cyclopentadienyl ring that acts as a tripodal ligand, $\left[\mathrm{CH}_{3} \mathrm{C}\left(\mathrm{CH}_{2}-\eta^{5}-\mathrm{C}_{5} \mathrm{H}_{4}\right)\left(\mathrm{CH}_{2} \mathrm{PPh}_{2}\right)_{2} \mathrm{MoO}\right]^{+}$, has been obtained by irradiation of $\left[\mathrm{CH}_{3} \mathrm{C}\left(\mathrm{CH}_{2}-\eta^{5}-\mathrm{C}_{5} \mathrm{H}_{4}\right)\left(\mathrm{CH}_{2} \mathrm{PPh}_{2}\right)_{2} \mathrm{Mo}(\mathrm{CO})_{2} \mathrm{I}\right]$ in the presence of air [116]. Higher oxidation state versions of these compounds have not been described. On the other hand, a 1-electron reduced version of $\left[\mathrm{CpMoO}\left(\mathrm{PMe}_{3}\right)_{2}\right]^{+}$, the neutral $\mathrm{Mo}^{\mathrm{III}}$ compound $\left[\mathrm{CpMoO}\left(\mathrm{PMe}_{3}\right)_{2}\right]$, has been spectroscopically identified in solution [113].

\section{Imido complexes}

$\mathrm{M}(\mathrm{V})$ imido compounds have been obtained from cyclopentadienyl containing precursors by direct exchange of two $\mathrm{M}-\mathrm{Cl}$ bonds with a primary amine, for instance $\left[\left(\mathrm{C}_{5} \mathrm{H}_{4} \mathrm{R}\right) \mathrm{M}\left(\mathrm{NR}^{\prime}\right) \mathrm{Cl}_{2}\right]$ from $\left[\left(\mathrm{C}_{5} \mathrm{H}_{4} \mathrm{R}\right) \mathrm{MCl}_{4}\right]$ and three equivalents of $\mathrm{R}^{\prime} \mathrm{NH}_{2}[91,117]$. The same procedure starting from oxido functionalities is unsuccessful. However, oxido ligands 
may be transformed into imido ligands by use of isocyanates (see section 4.4). M(VI) derivatives are more easily prepared by ion metathesis, e.g. $\left[\mathrm{CpM}(\mathrm{N} t \mathrm{Bu})_{2} \mathrm{Cl}\right](\mathrm{M}=\mathrm{Mo}, \mathrm{W})$ from $\left[\mathrm{Mo}(\mathrm{N} t \mathrm{Bu})_{2} \mathrm{Cl}_{2}\right]$ or $\left[\mathrm{W}(\mathrm{N} t \mathrm{Bu})_{2} \mathrm{Cl}_{2}(\mathrm{py})_{2}\right]$ and $\mathrm{CpLi}$ or $\mathrm{CpNa}[118]$.

\section{Sulfido and other chalcogenido complexes}

Compounds $\left[\left(\mathrm{Cp}^{*} \mathrm{M}\right) \mathrm{S}(\mu-\mathrm{S})\right],\left[\left(\mathrm{Cp}^{*} \mathrm{MS}\right)_{2}\left(\mu-\mathrm{S}_{2}\right)\right](\mathrm{M}=\mathrm{Mo}, \mathrm{W})$ and $\left[\mathrm{Cp}^{*} \mathrm{WS}_{3}\right]^{-}$are obtained from [Cp* $\mathrm{MCl}_{4}$ ] and $\mathrm{H}_{2} \mathrm{~S}$ [91], but the best synthetic procedures leading to sulfido derivatives involve the use of reagents containing $\mathrm{S}-\mathrm{S}$ or $\mathrm{S}-\mathrm{C}$ bonds and anhydrous conditions, as shown in Scheme $7[119,120]$. The reaction of $\left[\mathrm{Cp} * \mathrm{MoCl}_{4}\right]$ with $\mathrm{Li}_{2} \mathrm{~S}_{2}$ furnishes $[(\mathrm{Cp} * \mathrm{Mo}) \mathrm{S}(\mu-\mathrm{S})]_{2}$ selectively, whereas the same reaction on the $\mathrm{W}$ analogue yields a mixture of $[(\mathrm{Cp} * \mathrm{~W}) \mathrm{S}(\mu-\mathrm{S})]_{2}$ and $\left[\mathrm{Cp}^{*} \mathrm{WS}_{3}\right]^{-}$(isolated as the $\mathrm{PPh}_{4}{ }^{+}$salt) [120]. The use of $\mathrm{Li}_{2} \mathrm{~S}$ would seem more appropriate to obtain the $\mathrm{M}^{\mathrm{V}}$ product by direct ligand exchange, but this reaction produced in fact an inseparable mixture containing ill-defined compounds. The best method to synthesize the dinuclear $\mathrm{W}^{\mathrm{V}}$ product uncontaminated by the trisulfido $\mathrm{W}^{\mathrm{VI}}$ product is to react $\left[\mathrm{Cp}^{*} \mathrm{WCl}_{4}\right]$ with $\mathrm{LiSt} \mathrm{Bu}$ in $\mathrm{THF}$ and wait several hours at room temperature. At shorter reaction times, compound $\left[\mathrm{Cp}^{*} \mathrm{WS}_{2}(\mathrm{St} \mathrm{Bu})\right]$ is also detected as an intermediate and can be isolated in reasonable yields if the reaction is stopped after $1 \mathrm{~h}$. The corresponding reaction on $\left[\mathrm{Cp}^{*} \mathrm{MoCl}_{4}\right]$ leads to $\left[\mathrm{Cp} * \mathrm{Mo}(\mathrm{StBu})_{3}\right]$ as a result of metathesis and metal reduction. A selective method to obtain the trisulfido $\mathrm{W}^{\mathrm{VI}}$ complex selectively, on the other hand, is the reaction of $\left[\mathrm{Cp}^{*} \mathrm{WCl}_{4}\right]$ with $\mathrm{LiSCH}_{2} \mathrm{CH}_{2} \mathrm{SLi}$ in $\mathrm{THF}$ at $0^{\circ} \mathrm{C}$, whereas the corresponding reaction of $\left[\mathrm{Cp}^{*} \mathrm{MoCl}_{4}\right]$ leaves the $\mathrm{S}-\mathrm{C}$ bonds intact, yielding $\left[\mathrm{Cp}^{*} \mathrm{Mo}\left(\mathrm{SCH}_{2} \mathrm{CH}_{2} \mathrm{~S}\right)_{2}\right]^{-}[119,120]$.

The collective results shown in Scheme 7 highlight the greater stability of Mo systems in lower oxidation states and that of $\mathrm{W}$ systems in higher oxidation states. Indeed, the reactions with thiolate reagents, $\mathrm{RS}^{-}$, tend to lead to metal reduction for Mo (the electrons being presumably provided by the concomitant formation of RSSR) and to oxidation for W 
(with homolytic splitting of S-C bonds). Sulfido-based Mo ${ }^{\mathrm{VI}}$ systems (missing in Scheme 7) could eventually be prepared by oxidation of $\left[\mathrm{Cp} * \mathrm{Mo}(\mathrm{S} t \mathrm{Bu})_{3}\right]$ with $\mathrm{S}_{8}$. This reaction yields 4 different compounds, including $\left[\left(\mathrm{Cp}^{*} \mathrm{Mo}\right) \mathrm{S}(\mu-\mathrm{S})\right]_{2}, \quad\left[\mathrm{Cp}^{*} \mathrm{MoS}_{2}(\mathrm{St} \mathrm{Bu})\right] \quad$ and $[\mathrm{Cp} * \operatorname{MoOS}(\mathrm{S} t \mathrm{Bu})]$, the last two containing $\mathrm{Mo}^{\mathrm{VI}}$. Finally, the reaction of $\left[\mathrm{Cp}^{*} \mathrm{MoS}_{2}(\mathrm{St} \mathrm{Bu})\right]$ with $\mathrm{Li}_{2} \mathrm{~S}_{2}$ leads to $\left[\mathrm{Cp}^{*} \mathrm{MoS}_{3}\right]^{-}$, isolated in $65 \%$ yield as the $\mathrm{PPh}_{4}{ }^{+}$salt [120].

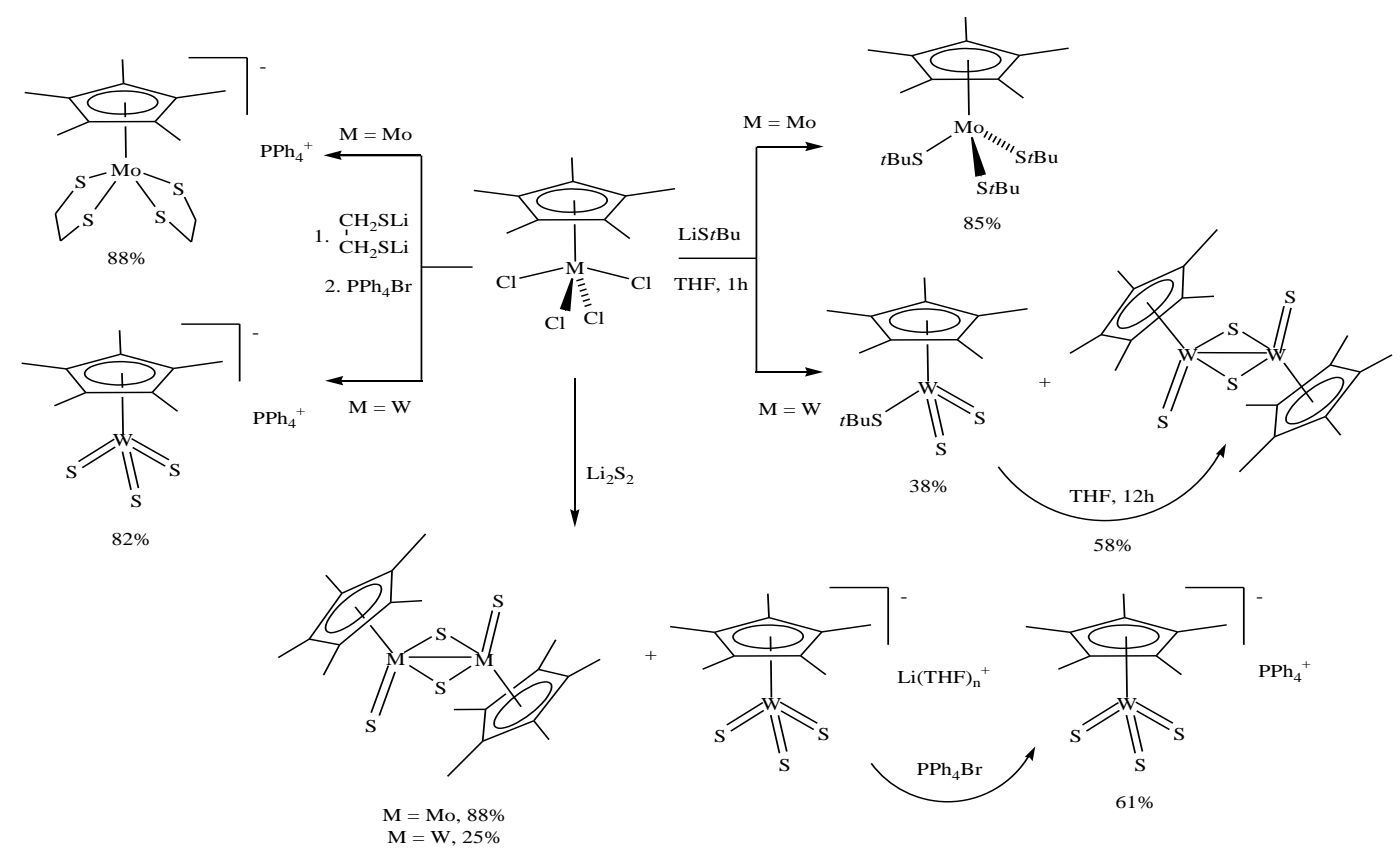

Scheme 7

Selenido derivatives have also been prepared. By analogy with the sulfido systems, reaction of $\left[\mathrm{Cp}^{*} \mathrm{WCl}_{4}\right]$ with $\mathrm{LiSe} t \mathrm{Bu}$ in $\mathrm{THF}$ at $-78^{\circ} \mathrm{C}$ immediately gives a red solution, which evolves to brown $\left[\left(\mathrm{Cp}^{*} \mathrm{~W}\right) \mathrm{Se}(\mu-\mathrm{Se})\right]_{2}(40 \%)$ over 30 min. However, $\mathrm{Li}_{2} \mathrm{Se}_{2}$ addition immediately after the initial reaction, followed by cation exchange with $\mathrm{PPh}_{4} \mathrm{Br}$, led to $\mathrm{PPh}_{4}\left[\mathrm{Cp}^{*} \mathrm{WSe}_{3}\right](23 \%)$, together with the dinuclear $\mathrm{W}^{\mathrm{V}}$ product [121].

A mixture of compounds $\mathrm{PPh}_{4}\left[\mathrm{Cp}^{*} \mathrm{WS}_{3}\right]$ and $\mathrm{PPh}_{4}\left[\mathrm{Cp}^{*} \mathrm{WSe}_{3}\right]$ in $\mathrm{MeCN}$ did not show any sign of ligand scrambling to form mixed sulfido-selenido complexes over an extended period of time. This prompted the researcher to develop a selective synthesis of the mixed [Cp*WOSSe] ${ }^{*}[122]$. The first step is the selective and high yield (89\%) synthesis of 
[Cp* $\left.\mathrm{WS}_{2} \mathrm{Cl}\right]$ by reaction of $\left[\mathrm{Cp}^{*} \mathrm{WCl}_{4}\right]$ with 1 equiv of $\mathrm{Me}_{3} \mathrm{SiSCH}_{2} \mathrm{CH}_{2} \mathrm{SSiMe}_{3}$, with appears to be a milder reagent than the dilithium salt ( $c f$. Scheme 7). Then, this compound is converted to $\left[\mathrm{Cp}^{*} \mathrm{WOS}_{2}\right]^{-}$by controlled hydrolysis in THF in the presence of $\mathrm{NEt}_{3}$, and isolated as the $\mathrm{PPh}_{4}{ }^{+}$salt in $77 \%$ yield. Subsequent alkylation with $\mathrm{MeI}$ of $\mathrm{BzBr}$ in $\mathrm{MeCN}$ gives $[\mathrm{Cp} * \mathrm{WOS}(\mathrm{SR})](\mathrm{R}=\mathrm{Me}, 98 \% ; \mathrm{Bz}, 92 \%)$. Finally, a terminal selenide was introduced by reaction with $\mathrm{Li}_{2} \mathrm{Se}_{2} / \mathrm{PPh}_{4} \mathrm{Br}$, affording $\mathrm{PPh}_{4}[\mathrm{Cp} *$ WOSSe] in 64 or $57 \%$ yields, respectively [122].

\subsection{Speciation studies}

Investigations in this area have so far been limited to the $\mathrm{Cp}^{*} \mathrm{Mo}^{\mathrm{VI}}$ system. Compound $\left[\mathrm{Cp}_{2}{ }_{2} \mathrm{Mo}_{2} \mathrm{O}_{5}\right]$ is insoluble in pure water. However, it is rather soluble in $\mathrm{MeOH}$ and sufficient amounts remain dissolved in a mixed 20:80 $\mathrm{MeOH}-\mathrm{H}_{2} \mathrm{O}$ solvent (up to ca. $5 \cdot 10^{-4} \mathrm{M}$ ) to allow spectroscopic investigations in the entire $\mathrm{pH}$ range [80]. The nature of the compound (Scheme 8) depends on the solvent, as shown by electrical conductivity studies [80]. In highly aqueous media, the compound self-ionizes to yield $\left[\mathrm{Cp}^{*} \mathrm{MoO}_{2}\left(\mathrm{H}_{2} \mathrm{O}\right)\right]^{+}\left[\mathrm{Cp}^{*} \mathrm{MoO}_{3}\right]^{-}$, whereas it maintains its neutral molecular form in organic solvents. Several X-ray diffraction studies of the molecular form have been published [81-83], and the structure of the trioxide anion (as the sodium salt) has also been recently reported [96]. A similar ionic dissociation was also demonstrated for the chlorido derivative, Scheme 8 [80].
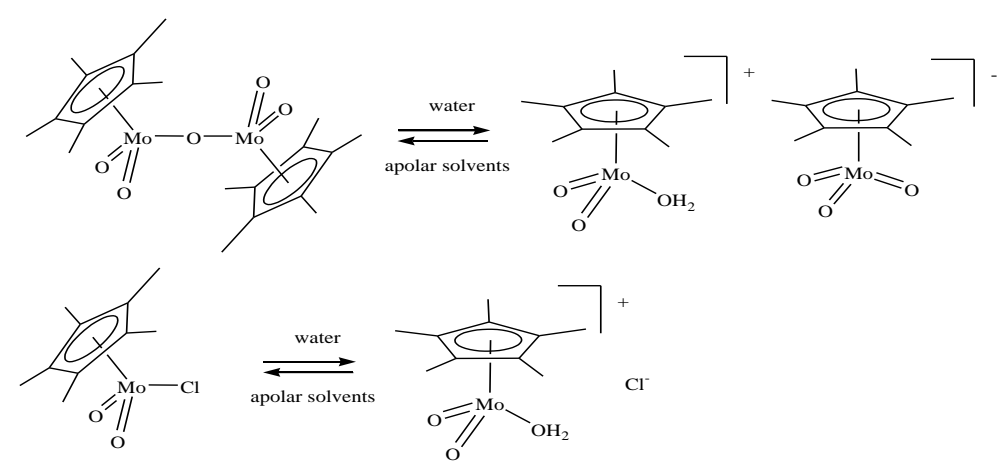


\section{Scheme 8}

Combined kinetics and equilibrium studies yield the speciation picture shown in Figure $1[80,123]$. Rapid protonation of $\left[\mathrm{Cp}^{*} \mathrm{MoO}_{3}\right]^{-}$with strong acids initially yields a $\mathrm{pH}-$ dependent species distribution as shown in Figure $1(\mathrm{a})$, where the $\left[\mathrm{Cp} * \mathrm{MoO}_{2}(\mathrm{OH})\right]$ complex predominates at low $\mathrm{pH}$. The solution then evolves toward a $\mathrm{pH}$-dependent equilibrium, shown in Figure 1(b), with a rate which is first order in $\left[\mathrm{H}^{+}\right]$(at low $\mathrm{pH}$ ) via the unstable $\left[\mathrm{Cp} * \mathrm{MoO}(\mathrm{OH})_{2}\right]^{+}$species. The acid dissociation constant of $\left[\mathrm{Cp}^{*} \mathrm{MoO}_{2}(\mathrm{OH})\right]\left(\mathrm{p} K_{\mathrm{a} 2}=3.65\right)$ was obtained from the analysis of the absorption at time zero at various $\mathrm{pH}$, whereas the acid dissociation of unstable $\left[\mathrm{Cp}^{*} \mathrm{MoO}(\mathrm{OH})_{2}\right]^{+}\left(p \mathrm{~K}_{\mathrm{a} 1}=-0.56\right)$ could be deduced from accurate kinetics carried out at very low $\mathrm{pH}[123]$. The basic form, $\left[\mathrm{Cp} * \mathrm{MoO}_{3}\right]^{-}$, remains the only species at $\mathrm{pH}>6$, whereas the thermodynamically stable acidic form, $\left[\mathrm{Cp}^{*} \mathrm{MoO}_{2}\left(\mathrm{H}_{2} \mathrm{O}\right)\right]^{+}$, dominates at $\mathrm{pH}<2$. In the intermediate $\mathrm{pH}$ range, both forms are present and a minor amount of neutral $\left[\mathrm{Cp}^{*} \mathrm{MoO}_{2}(\mathrm{OH})\right]$ also remains present at equilibrium.
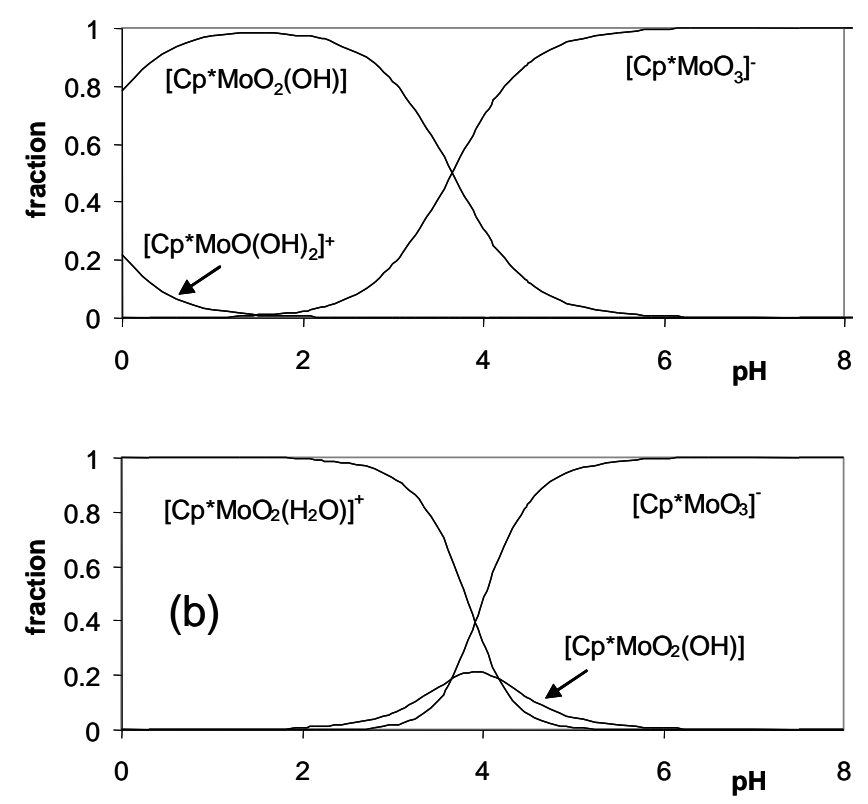

Figure 1. Speciation of $\mathrm{Cp}^{*} \mathrm{Mo}^{\mathrm{VI}}$ in $20: 80 \mathrm{MeOH}-\mathrm{H}_{2} \mathrm{O}$ : (a) before isomerization of $\left[\mathrm{Cp} * \mathrm{MoO}(\mathrm{OH})_{2}\right]^{+} ;($b) at equilibrium. 
The opposite transformation of $\left[\mathrm{Cp}^{*} \mathrm{MoO}_{2}\left(\mathrm{H}_{2} \mathrm{O}\right)\right]^{+}$to $\left[\mathrm{Cp}^{*} \mathrm{MoO}_{3}\right]^{-}$shows a first order dependence on $\left[\mathrm{OH}^{-}\right]$in the high $\mathrm{pH}$ range [80]. From all the above studies, Scheme 9 could be derived. This means that interconversion between $\left[\mathrm{Cp}^{*} \mathrm{MoO}_{2}\left(\mathrm{H}_{2} \mathrm{O}\right)\right]^{+}$and $\left[\mathrm{Cp}^{*} \mathrm{MoO}_{3}\right]^{-}$ follows two parallel pathways, of which one $\left(k_{+1} / k_{-1}\right)$ prevails at high $\mathrm{pH}$ and the other one $\left(k_{+2} / k_{-2}\right)$ is dominant at low $\mathrm{pH}$. Note that the $\left(k_{+1} / k_{-1}\right) K_{\mathrm{s}}$ expression corresponds to the acid dissociation constant of the aqua cation $\left[\mathrm{Cp}^{*} \mathrm{MoO}_{2}\left(\mathrm{H}_{2} \mathrm{O}\right)\right]^{+}\left(\mathrm{p} K_{\mathrm{a} 1},=4.19\right)$. Hence, the apparent first acid dissociation of the stable acidic species, $\left[\mathrm{Cp}^{*} \mathrm{MoO}_{2}\left(\mathrm{H}_{2} \mathrm{O}\right)\right]^{+}$, is in fact weaker than the second one. This is because the aqua ligand is weakly bonded to the Mo centre and a rapid equilibrium with unsolvated $\left[\mathrm{Cp} * \mathrm{MoO}_{2}\right]^{+}$is established. Thus, the effective thermodynamic acidity is a weighted average of the high intrinsic acidity of the coordinated water molecule and the low acidity of free water [123]. The $k_{+2} / k_{-2}$ ratio, on the other hand, represents the isomerization equilibrium constant: the free energy difference between $\left[\mathrm{Cp}^{*} \mathrm{MoO}_{2}\left(\mathrm{H}_{2} \mathrm{O}\right)\right]^{+}$and its less stable isomer $\left[\mathrm{Cp}^{*} \mathrm{MoO}(\mathrm{OH})_{2}\right]^{+}$is $6.5 \mathrm{kcal} / \mathrm{mol}$. As it turns out, a definite formulation of the stable acidic species as a solvated $\left(\left[\mathrm{Cp}^{*} \mathrm{MoO}_{2}\left(\mathrm{H}_{2} \mathrm{O}\right)\right]^{+}\right)$ or unsolvated $\left(\left[\mathrm{Cp}^{*} \mathrm{MoO}_{2}\right]^{+}\right)$species remained ambiguous after the initial study [80]. Evidence gathered in the subsequent study [123], which was backed up by DFT calculations, confirmed the stabilization of the species by $\mathrm{H}_{2} \mathrm{O}$ coordination.

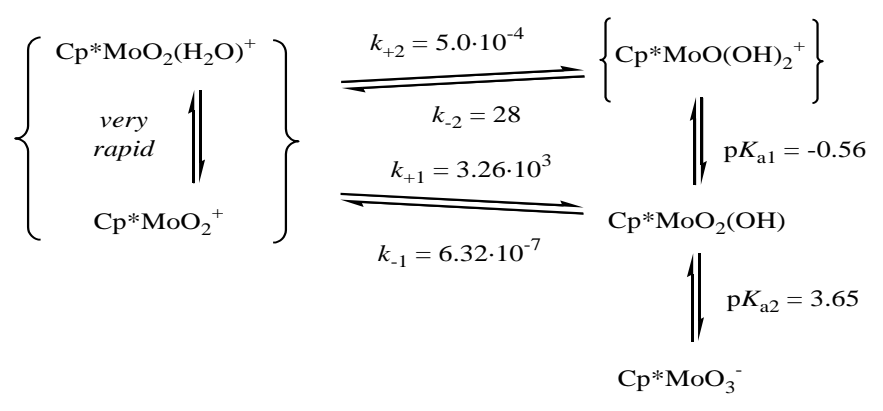

Scheme 9

\subsection{Reductive chemistry}


Like for the synthetic work, the early chemical reduction studies of high oxidation state organometallic Mo and $\mathrm{W}$ compounds were carried out under anhydrous conditions. Thus, compound $\left[\mathrm{Cp}_{2} \mathrm{Mo}_{2} \mathrm{O}_{5}\right]$ is reduced by anhydrous $\mathrm{HX}$ to $\left[\mathrm{CpMoX}_{4}\right](\mathrm{X}=\mathrm{Cl}[68], \mathrm{Br}[9])$ and by $\mathrm{PPh}_{3}$ to $\left[\mathrm{Cp}_{2} \mathrm{Mo}_{2} \mathrm{O}_{4}\right]$ [71]. Compound $\left[\mathrm{Cp}^{*} \mathrm{MoO}_{2} \mathrm{Cl}\right]$ is reduced by $\mathrm{P}(\mathrm{OMe})_{3}$ to $\left[\left(\mathrm{Cp}^{*} \mathrm{MoOCl}\right)_{2}(\mu-\mathrm{O})\right][92]$. Stronger reducing agents $\left(\mathrm{Na}, \mathrm{Zn}, \mathrm{Sn}\right.$, etc.) convert $\left[\mathrm{Cp}^{*} \mathrm{MCl}_{4}\right]$ complexes to $\left[\mathrm{Cp}^{\prime} \mathrm{MCl}_{3}\right]_{2}$ and $\left[\mathrm{Cp}^{\prime} \mathrm{MCl}_{2}\right]_{2},[76,124-130]$ which are convenient starting materials for further synthetic work. Reductive studies of cyclopentadienyl imido precursors in anhydrous solvents have given access to a number of organometallic derivatives containing $\pi$ ligands (alkenes, alkynes, ...), mostly in the oxidation state IV [117, 131].

The reduction of $\mathrm{Cp}^{\prime} \mathrm{Mo}^{\mathrm{V}}$ and $\mathrm{Cp}^{\prime} \mathrm{Mo}^{\mathrm{VI}}$ chlorido and mixed oxido-chlorido compounds has been investigated as a general entry into metal clusters. The reduction of $\left[\mathrm{CpMoOCl}_{2}\right]$ with zinc in tetrahydrofuran gives a poorly characterized diamagnetic product, described as tetranuclear mixed-valence $\left[(\mathrm{CpMoCl})_{4} \mathrm{O}_{6}(\mathrm{ZnCl}(\mathrm{THF}))_{2}\right]$ (average oxidation state of 4.25 ), which is reoxidized in air to afford the $\mathrm{Mo}^{\mathrm{V}}$ product $\left[(\mathrm{CpMoOCl})_{2}(\mu-\mathrm{O})\right]$ [72]. Upon changing the ring to $\mathrm{Cp}^{*}$, a similar strategy (sodium or magnesium amalgam, $\mathrm{Mg}$ turnings, or $\left.n \mathrm{Bu}_{3} \mathrm{SnH}\right)$ led to the formation of tetranuclear mixed-valence $\left[\left(\mathrm{Cp}^{*} \mathrm{Mo}\right)_{4}(\mu-\mathrm{O})_{6}\left(\mu_{3}-\mathrm{O}\right)\right]$ (average oxidation state of 4.5$)$, starting from either $\left[\mathrm{Cp}^{*} \mathrm{MoOCl}_{2}\right]$ or $\left[(\mathrm{Cp} * \mathrm{MoOCl})_{2}(\mu-\mathrm{O})\right]$ [132]. On the other hand, reduction of $\left[\mathrm{Cp}^{*} \mathrm{MoO}_{2} \mathrm{Cl}\right]$ with $\mathrm{Zn}$ in $\mathrm{HCl} / \mathrm{CHCl}_{3}$ gives a trinuclear cluster, described as having formula $\left[\left(\mathrm{Cp}^{*} \mathrm{Mo}\right)_{3}(\mu-\mathrm{OH})_{\mathrm{n}}(\mu-\mathrm{O})_{6-\mathrm{n}}\right] \mathrm{Cl}_{2}$. This material was characterized by elemental analysis, mass spectrometry, IR, NMR and EPR spectroscopies, and by a poor quality single-crystal X-ray diffraction experiment, which could not directly determine the number of $\mathrm{H}$ atoms on the bridging $\mathrm{O}$ ligands. The collective results were interpreted as consistent with an average $n$ value of 5 and with the presence of a redox-equilibrium between the $n=5$ cluster $\left(\mathrm{Mo}_{3}{ }^{12+}, 6\right.$ cluster electrons) and two additional clusters having $n=4\left(\mathrm{Mo}_{3}{ }^{13+}, 5\right.$ cluster electrons) and $n=6\left(\mathrm{Mo}_{3}{ }^{11+}, 7\right.$ cluster electrons) [133]. 
Since more recent work (vide infra) helps perhaps clarify the nature of these reduced clusters, it is worth briefly summarizing their electronic structure. The geometry of the $\left[(\mathrm{Cp} * \mathrm{Mo})_{3}(\mu-\mathrm{OH})_{\mathrm{n}}(\mu-\mathrm{O})_{6-\mathrm{n}}\right]^{2+}$ cluster is related to that of the $\left[(\mathrm{Cp} * \mathrm{Re})_{3}(\mu-\mathrm{O})_{6}\right]^{2+}$ cluster (a $\mathrm{Re}_{3}{ }^{17+}$, 4-electron cluster), which was analyzed by theoretical calculations at the extended Huckel and SCF X $\alpha-S W$ levels $[134,135]$. The electronic structure of this system can actually be easily understood starting from that of the individual four-legged piano stool "Cp* $\mathrm{MO}_{4}$ " fragments, which leaves two metal-based orbitals available for metal-metal bonding: a lower energy $x y$ orbital and a higher-energy $z^{2}$ orbital [136]. Assembly of three such units in a $D_{3 h}$ arrangement generates the metal-metal interactions illustrated in Figure 2. The most important interaction is the mixed $\sigma / \pi$-type overlap of the three $z^{2}$ orbitals, yielding a bonding $a$-type orbital and two degenerate antibonding $e$-type orbitals. A similar type of interaction also occurs for the three $x y$ orbitals, this having however a much weaker mixed $\pi / \delta$-type overlap. As a result, both $a$-type and $e$-type molecular orbitals originating from the overlap of the atomic $x y$ orbitals are essentially non bonding and do not contribute significantly to the strength of the metal-metal interaction. The $a(x y)$ combination (slightly $\mathrm{M}-\mathrm{M}$ bonding) is in fact higher in energy than the two degenerate $e(x y)$ combinations (slightly M-M antibonding), because of a stronger participation to this orbital of the six bridging $\mathrm{O}$ lone pairs in the antiphase mode (M-O $\pi^{*}$ type). The prediction on the basis of this electronic structure is that a 6-electron cluster should be diamagnetic (and show a sharp NMR Cp* resonance), a 7-electron cluster should have a single unpaired electron in the non-degenerate $a(x y)$ orbitals (and show a sharp EPR spectrum at ambient temperature and no NMR resonances), whereas a 5-electron cluster should also be paramagnetic but, being the unpaired electron in a degenerate orbital (configuration $e(x y)^{3}$ ), no EPR spectrum would be expected at ambient temperature and perhaps broadened but visible paramagnetically shifted NMR resonances could be observed. The observation of all these features (one sharp NMR signal, one broadened NMR signals, and a sharp EPR signal) was the main factor leading to the 
proposition of the redox-equilibrium. Furthermore, a low (ca. $1.13 \mu_{\mathrm{B}}$ ) and nearly temperature-independent magnetic moment in the $4-85 \mathrm{~K}$ range led the authors to calculate that approximately $35 \%$ of the total sample is diamagnetic [133].

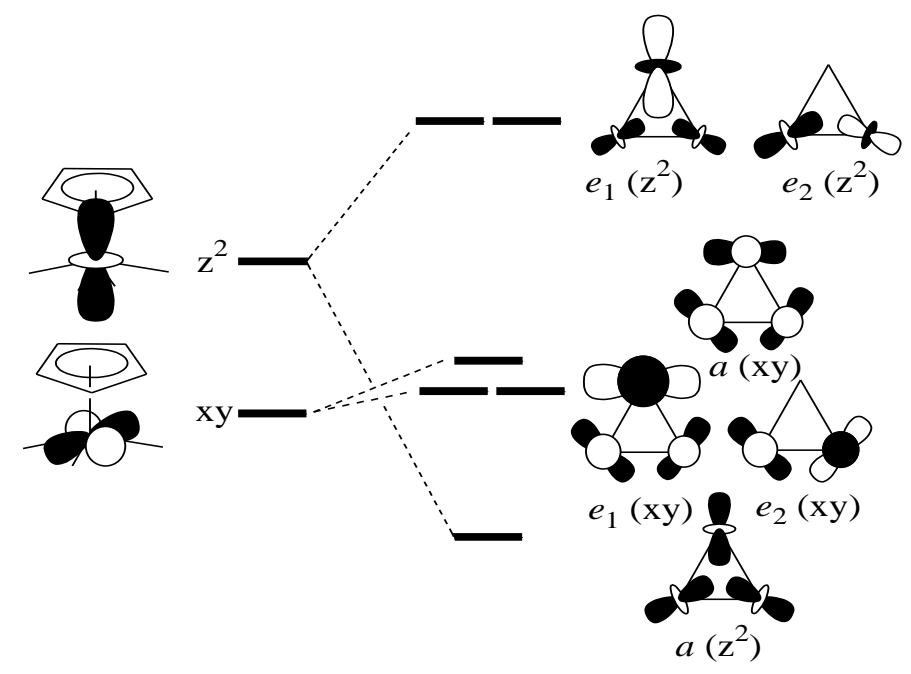

Figure 2. Energy diagram relating the electronic structure of a $\left[\left(\mathrm{Cp}^{*} \mathrm{M}\right)(\mu-\mathrm{O})_{6}\right]^{\mathrm{n}+}$ cluster in ideal $D_{3 h}$ symmetry with that of the three individual " $\mathrm{Cp} * \mathrm{MO}_{4}$ " moieties.

In our own laboratory, we have investigated the chemical and electrochemical reduction of $\left[\mathrm{Cp}^{*}{ }_{2} \mathrm{M}_{2} \mathrm{O}_{5}\right](\mathrm{M}=\mathrm{Mo}, \mathrm{W})$ in aqueous media. Whereas compound $\left[\mathrm{Cp}^{*} \mathrm{MoO}_{2} \mathrm{Cl}\right]$ is described as unstable as a solid, its decomposition to insoluble blue materials being accelerated by traces of moisture and light, compounds $\left[\mathrm{Cp}^{*}{ }_{2} \mathrm{M}_{2} \mathrm{O}_{5}\right]$ does not show any sign of deterioration in the typical laboratory atmosphere (presence of moisture and light) and may be stored indefinitely. The formation of blue decomposition products from $\left[\mathrm{Cp}^{*}{ }_{2} \mathrm{Mo}_{2} \mathrm{O}_{5}\right]$ was only observed in non-aqueous solvents and in the presence of strong acids. Therefore, the dinuclear pentaoxido compounds are more convenient starting materials for reactions in aqueous media.

Initial reduction studies were carried out electrochemically on $\left[\mathrm{Cp}_{2}{ }_{2} \mathrm{Mo}_{2} \mathrm{O}_{5}\right]$ in a mixed $\mathrm{MeOH}-\mathrm{H}_{2} \mathrm{O}$ solvent, using a special flow-though cell directly connected to an on-line electrospray ionization mass spectrometer (ESI-MS). These experiments unveiled a great 
complexity, with a host of new mononuclear, dinuclear, trinuclear and even higher aggregation products being formed, which further depend on the $\mathrm{pH}$ and on the nature of the counterion used in the supporting electrolyte [137, 138]. At pH 4 (acetic acid/acetate buffer), species $\left[\mathrm{Cp}^{*} \mathrm{Mo}^{\mathrm{V}} \mathrm{O}(\mathrm{OAc})\right]^{+}, \quad\left[\mathrm{Cp}^{*} \mathrm{Mo}(\mathrm{OAc})_{2}\right]^{+}, \quad\left[\left(\mathrm{Cp}^{*} \mathrm{Mo}^{\mathrm{V}}\right)_{2}(\mathrm{O})_{3}(\mathrm{OH})\right]^{+}, \quad\left[\left(\mathrm{Cp}^{*} \mathrm{Mo}^{\mathrm{V}}\right)_{2}(\mathrm{O})_{3^{-}}\right.$ $(\mathrm{OAc})]^{+},\left[\left(\mathrm{Cp}^{*} \mathrm{Mo}^{\mathrm{V}}\right)\left(\mathrm{Cp}^{*} \mathrm{Mo}^{\mathrm{IV}}\right)(\mathrm{O})_{2}(\mathrm{OAc})_{2}\right]^{+},\left[\left(\mathrm{Cp}^{*} \mathrm{Mo}^{\mathrm{IV}}\right)_{2}(\mathrm{O})(\mathrm{OAc})_{3}\right]^{+}$, and $\left[\left(\mathrm{Cp}^{*} \mathrm{Mo}\right)_{3}(\mathrm{O})_{6}\right]^{+}$ $\left(\mathrm{a} \mathrm{Mo}_{3}{ }^{16+}\right.$, 2-electron cluster) were clearly identified $\left(\mathrm{OAc}=\mathrm{CH}_{3} \mathrm{CO}_{2}\right)$ [137]. At $\mathrm{pH} 1$ (trifluoroacetic acid solution) many of the same species (with $\mathrm{CF}_{3} \mathrm{CO}_{2}$ in place of $\mathrm{CH}_{3} \mathrm{CO}_{2}$ ) were again obtained, but also lower oxidation state products such as $\left[\left(\mathrm{Cp}^{*} \mathrm{Mo}^{\mathrm{III}}\right)_{2}(\mathrm{OH})-\right.$ $\left.\left(\mathrm{O}_{2} \mathrm{CCF}_{3}\right)_{2}\right]^{+},\left[(\mathrm{Cp} * \mathrm{Mo})_{3}(\mathrm{O})_{5}\right]^{+}\left(\mathrm{a} \mathrm{Mo}_{3}{ }^{14+}\right.$, 4-electron cluster $)$ and $\left[\left(\mathrm{Cp}^{*} \mathrm{Mo}\right)_{3}(\mathrm{O})_{4}\right]^{+}\left(\mathrm{a} \mathrm{Mo}_{3}{ }^{12+}\right.$, 6-electron cluster) [138]. Lower $\mathrm{pH}$ leads to deeper reduction, as expected. It should be noted that the chosen ESI-MS technique restricts detection to positively charged species, thus the complexity of the reduction process may even be greater. This complex behaviour contrasts with the clean one-electron reduction process observed for complex $\left[\mathrm{Cp}^{*} \mathrm{Mo}_{6} \mathrm{O}_{18}\right]^{-}$ in $\mathrm{MeCN}$ [139].

Chemical reductions have subsequently been carried out in an attempt to isolate and characterized at least some of the electrochemically generated species. Indeed, compound $\left[\left(\mathrm{Cp}^{*} \mathrm{Mo}\right)_{2}(\mu-\mathrm{O})_{2}(\mu-\mathrm{OAc})_{2}\right]$ was isolated from the $\mathrm{Zn}$ reduction in acetic-buffered $\mathrm{MeOH}-$ $\mathrm{H}_{2} \mathrm{O}$ solution [140]. This product shows a reversible 1-electron oxidation process, yielding one of the species detected by the electrochemistry/ESI-MS experiment. When the same $\mathrm{Zn}$ reduction was carried out in a $\mathrm{CF}_{3} \mathrm{COOH}$-acidified $\mathrm{MeOH}-\mathrm{H}_{2} \mathrm{O}$ medium, compound $\left[\left(\mathrm{Cp}^{*} \mathrm{Mo}\right)_{3}(\mu-\mathrm{OH})_{4}(\mu-\mathrm{O})_{2}\right]^{2+}\left(\mathrm{O}_{2} \mathrm{CCF}_{3}\right)_{2}$ was isolated in pure form [141]. Note that this reaction is closely related to that reported by Bottomley et al. [133], the only differences being the reaction solvent and the absence of $\mathrm{Cl}$ in the starting material and in the added acid. The determination of the number of protons on the bridging $\mathrm{O}$ atoms was again problematic, because the quality of the structure did not allow their direct location. However, the presence of $4 \mathrm{H}$-bonds with the $4 \mathrm{O}$ atoms of the anions (see Figure 3 ) indirectly proves the presence of 
at least $4 \mathrm{OH}$ groups. In order to verify whether additional protons are present on the two residual bridging $\mathrm{O}$ atoms, the reaction was repeated with $\mathrm{CF}_{3} \mathrm{SO}_{3} \mathrm{H}$, keeping in mind that the three $\mathrm{O}$ groups of the $\mathrm{CF}_{3} \mathrm{SO}_{3}{ }^{-}$anion on each side of the $\mathrm{Mo}_{3}$ triangle would be able to form $\mathrm{H}$-bonds with up to three $\mathrm{OH}$ groups if they were present. Once again, the $\mathrm{H}$ atoms could not be directly located by the X-ray structural analysis, but the presence of only two H-bond on each face of the $\mathrm{Mo}_{3}$ triangle argues very strongly in favour of the presence of only four bridging $\mathrm{OH}$ groups. A close look at the Mo-Mo distances in Figure 3 shows that the $\mathrm{Mo}(\mu-$ $\mathrm{O})(\mu-\mathrm{OH}) \mathrm{Mo}$ bonds are slightly shorter than the unique $\mathrm{Mo}(\mu-\mathrm{OH})_{2} \mathrm{Mo}$ bond, as expected, and all structural features were quite well reproduced by DFT calculations on the basis of the given formulation [141].
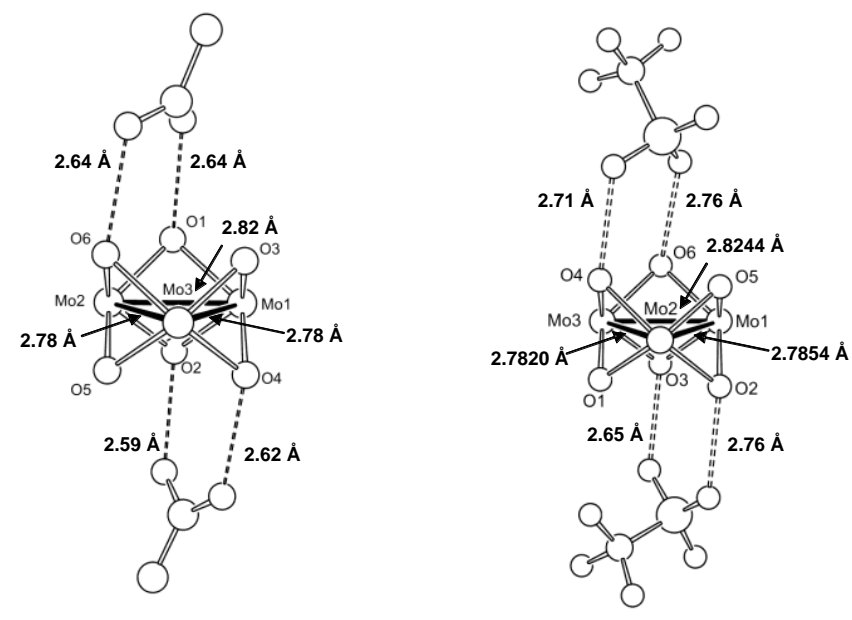

Figure 3. Structures of the $\left[\left(\mathrm{Cp}^{*} \mathrm{Mo}\right)_{3}(\mu-\mathrm{OH})_{4}(\mu-\mathrm{O})_{2}\right] \mathrm{X}_{2}$ compounds, emphasizing the cation-anion $\mathrm{H}$-bonds. Left: $\mathrm{X}=\mathrm{CF}_{3} \mathrm{CO}_{2}$; right: $\mathrm{X}=\mathrm{CF}_{3} \mathrm{SO}_{3}$. The $\mathrm{Cp}$ * ligands have been removed for clarity. Distances in red are those of the Mo-Mo bonds, those in bold black characters are those of the $\mathrm{H}$-bonded $\mathrm{O} \cdots \mathrm{O}$ contacts.

According to the electronic structure analysis given above and to the previous $\left[(\mathrm{Cp} * \mathrm{Mo})_{3}(\mu-\mathrm{OH})_{\mathrm{n}}(\mu-\mathrm{O})_{6-\mathrm{n}}\right]^{2+}$ report $[133]$, this $\left[(\mathrm{Cp} * \mathrm{Mo})_{3}(\mu-\mathrm{OH})_{4}(\mu-\mathrm{O})_{2}\right]^{2+}$ cluster should exhibit a broad NMR signal and no EPR signal. However, contrary to this prediction, the cluster (in both isolated salts) shows a sharp EPR spectrum in isotropic solution at room 
temperature and no NMR signal, neither broad nor sharp [141]. The EPR spectrum $(\mathrm{g}=$ $\left.1.962, a_{\mathrm{Mo}}=26.2 \mathrm{G}\right)$ is very similar to that shown [133] for compound $\left[\left(\mathrm{Cp}^{*} \mathrm{Mo}\right)_{3}(\mu-\mathrm{OH})_{\mathrm{n}}(\mu-\right.$ O) $\left.{ }_{6-\mathrm{n}}\right] \mathrm{Cl}_{2}\left(\mathrm{~g}=1.962, a_{\mathrm{Mo}}=\right.$ not reported $)$. The measured magnetic moment is $1.66 \mu_{\mathrm{B}}$ (relatively constant in the $4-60 \mathrm{~K}$ range), near the expected value for a $S=1 / 2$ system. Thus, these two salts do not undergo complex redox equilibria, differently from the behaviour proposed for $\left[\left(\mathrm{Cp}^{*} \mathrm{Mo}\right)_{3}(\mu-\mathrm{OH})_{\mathrm{n}}(\mu-\mathrm{O})_{6-\mathrm{n}}\right] \mathrm{Cl}_{2}$. An additional interesting observation concerns the simulation of the EPR spectrum. The one reported for $\left[\left(\mathrm{Cp}^{*} \mathrm{Mo}\right)_{3}(\mu-\mathrm{OH})_{\mathrm{n}}(\mu-\mathrm{O})_{6-\mathrm{n}}\right] \mathrm{Cl}_{2}$ was said to indicate coupling to three equivalent nuclei on the basis of the satellite intensities relative to the central resonance [133]. On the other hand, the simulated spectra for the two $\left[\left(\mathrm{Cp}^{*} \mathrm{Mo}\right)_{3}(\mu-\mathrm{OH})_{4}(\mu-\mathrm{O})_{2}\right]^{2+}$ clusters had too strong satellites, relative to the experimental spectrum, when using a coupling model to three equivalent Mo atoms, and too low when considering coupling to only a single Mo atom. The simulation perfectly fits the experimental spectrum when considering coupling to two equivalent Mo atoms [141]. A rationalization of this phenomenon was possible on the basis of the DFT electronic structure calculations. Because of the asymmetric nature of the bridge system, the point group symmetry is lowered from $D_{3 h}$ to $C_{2}$ with consequent splitting of the $e(x y)$ degeneracy into separate $e_{1}(x y)$ and $e_{2}(x y)$ orbitals (becoming respectively $a^{\prime}$ and $a^{\prime \prime}$ in $C_{2}$ ), the shapes of which remain close to those expected in $D_{3 h}$ symmetry (see Figure 2). The orbital ordering and occupation shown by the calculation is $a^{\prime}\left(z^{2}\right)^{2} a^{\prime}(x y)^{2} a^{\prime \prime}(x y)^{1}$, with the unpaired electron in the non-degenerate $a$ " $(x y)$ [formerly $e_{2}(x y)$ ] orbital, rationalizing the sharpness of the spectrum. This orbital has a nodal plane that contains one of the three Mo atoms, imposing a zero contribution of this atom's $x y$ orbital, even in the lower $C_{2}$ symmetry, and therefore rationalizing the observed coupling to only two Mo atoms [141].

A different cluster, $\left[(\mathrm{Cp} * \mathrm{Mo})_{3}\left(\mu_{3}-\mathrm{O}\right)(\mu-\mathrm{O})_{3}\left(\mu-\mathrm{O}_{2} \mathrm{CCF}_{3}\right)_{3}\right]^{+}$(crystallized as a salt of the $\left[\mathrm{Zn}_{2}\left(\mathrm{O}_{2} \mathrm{CCF}_{3}\right)_{6}\right]^{2-}$ ion) was also obtained from the same $\mathrm{Zn}$ reduction experiment described above, under different crystallization conditions and in small amounts, sufficient for an X-ray 
analysis but not for a thorough spectroscopic study except for an ESI-MS [142]. This is a $\mathrm{Mo}_{3}{ }^{15+}$, 3-electron cluster, namely less reduced relative to the 5-electron $\left[\left(\mathrm{Cp}^{*} \mathrm{Mo}\right)_{3}(\mu-\right.$ $\left.\mathrm{OH})_{4}(\mu-\mathrm{O})_{2}\right]^{2+}$ cluster described above. Possibly, the reduction process for this particular batch was incomplete. This result, together with the rich reductive electrochemistry shown by the coupled mass spectrometric analysis (vide supra), suggests that this family of clusters should undergo facile transformations involving addition/removal of protons, electrons, and water molecules. More detailed investigations of such transformations have not yet been carried out.

Reductive processes of $\mathrm{Cp}^{*} \mathrm{~W}^{\mathrm{VI}}$ starting materials have been much less investigated, perhaps because their synthesis was less convenient than that of their Mo counterparts. The recently developed aqueous route to $\left[\mathrm{Cp}^{*}{ }_{2} \mathrm{~W}_{2} \mathrm{O}_{5}\right]$ in high yields [96] (see section 4.1) has opened the way to more detailed investigations of this system in our laboratory. The electrochemical study of $\left[\mathrm{Cp}^{*}{ }_{2} \mathrm{~W}_{2} \mathrm{O}_{5}\right]$ by flow-through electrochemistry coupled to on-line ESI-MS detection was not as successful as the corresponding Mo study (vide supra). A more negative electrode potential was necessary to start reducing the complex, as expected from the greater stability of $\mathrm{W} v s$. Mo in the highest oxidation states. At this point, an insoluble film deposited on the electrode, blocking any further electrochemical process, and no reduced products could be detected by ESI-MS. Thus, it seems that any primary reduction product is unstable under these highly reducing conditions and proceeds further to yield insoluble products.

Greater success was achieved by chemical reduction with $\mathrm{Zn} / \mathrm{HA}$ in $\mathrm{MeOH}-\mathrm{H}_{2} \mathrm{O}(\mathrm{HA}=$ $\left.\mathrm{CF}_{3} \mathrm{COOH}, \mathrm{CF}_{3} \mathrm{SO}_{3} \mathrm{H}\right)$, i.e. the same protocol used previously for the Mo system [143]. The reduction leads to a green product, $\left[\left(\mathrm{Cp}^{*} \mathrm{~W}\right)_{3} \mathrm{O}_{4}(\mathrm{OH})_{2}\right]^{2+}\left(\mathrm{a} \mathrm{W}_{3}{ }^{15+}, 3\right.$-electron cluster), which is air sensitive and is oxidized in air to orange $\left[(\mathrm{Cp} * \mathrm{~W})_{3} \mathrm{O}_{6}\right]^{+}\left(\mathrm{a} \mathrm{W}_{3}{ }^{16+}\right.$, 2-electron cluster). Both products have been crystallographically characterized as triflate salts, see Figure 4. The problem of the number of $\mathrm{H}$ atoms on the bridge system is again indirectly solved by the 
analysis of the H-bonding interactions. The X-ray analysis actually allowed the location of the $\mathrm{H}$ atoms of the interstitial water molecules in the structure of $\left[(\mathrm{Cp} * \mathrm{~W})_{3}(\mu-\mathrm{O})_{4}(\mu-\right.$ $\left.\mathrm{OH})_{2}\right]\left(\mathrm{CF}_{3} \mathrm{SO}_{3}\right)_{2} \cdot 2 \mathrm{H}_{2} \mathrm{O}$, but not those on the bridging $\mathrm{OH}$ group, which are however revealed by the short $\mathrm{H}$-bonded contacts to the interstitial water molecules. The absence of $\mathrm{H}$ atoms on the other bridging $\mathrm{O}$ atoms is suggested by the absence of additional H-bonds. Likewise, the absence of bridging $\mathrm{OH}$ groups in the structure of $\left[(\mathrm{Cp} * \mathrm{~W})_{3}(\mu-\mathrm{O})_{6}\right]\left(\mathrm{CF}_{3} \mathrm{SO}_{3}\right)$ is suggested by the absence of cation-anion H-bonded contacts. As for the Mo cluster discussed above, the $\mathrm{W}-\mathrm{W}$ distances are consistent with the given formulation, the distance in the $\mathrm{W}(\mu-\mathrm{O})(\mu-$ $\mathrm{OH}) \mathrm{W}$ moiety being longer than that in the $\mathrm{W}(\mu-\mathrm{O})_{2} \mathrm{~W}$ moiety, and the latter one being essentially identical in the two compounds. This is also expected, because the two cluster differ by one electron located in an essentially W-W nonbonding orbital (one of the two orbitals of the $e(x y)$ set shown in Figure 2). The pattern of bond distances and angles in both clusters is reproduced very well by DFT geometry optimizations.

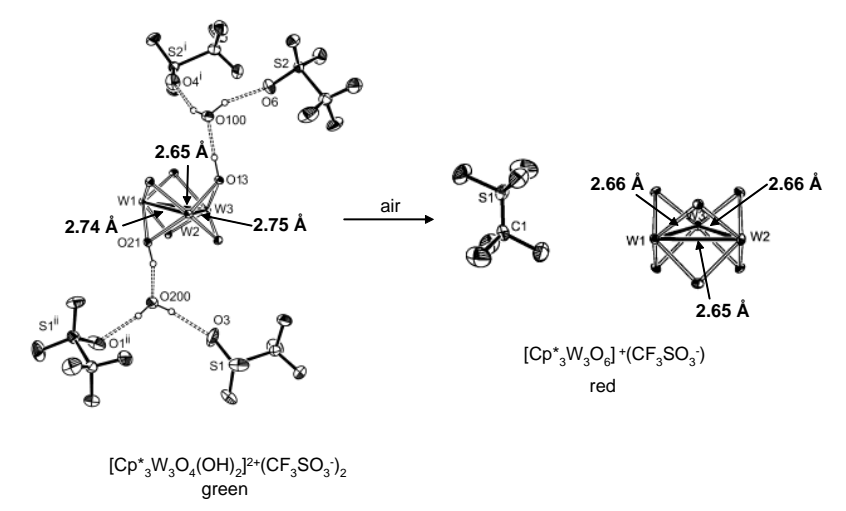

Figure 4. Structures of the $\left[(\mathrm{Cp} * \mathrm{~W})_{3}(\mu-\mathrm{O})_{4}(\mu-\mathrm{OH})_{2}\right]\left(\mathrm{CF}_{3} \mathrm{SO}_{3}\right)_{2} \cdot 2 \mathrm{H}_{2} \mathrm{O} \quad$ (left) and $\left[\left(\mathrm{Cp}^{*} \mathrm{~W}\right)_{3}(\mu-\mathrm{O})_{6}\right]\left(\mathrm{CF}_{3} \mathrm{SO}_{3}\right)$ (right), emphasizing the cation-anion $\mathrm{H}$-bonds in the former. The $\mathrm{Cp}^{*}$ ligands have been removed for clarity. Distances in red are those of the Mo-Mo bonds, those in bold black characters are those of the $\mathrm{H}$ bonded $\mathrm{O} \cdots \mathrm{O}$ contacts.

Complex $\left[(\mathrm{Cp} * \mathrm{~W})_{3}(\mu-\mathrm{O})_{6}\right]^{+}$is diamagnetic, consistent with the expected $\left[a\left(\mathrm{z}^{2}\right)\right]^{2}$ formulation and shows a single $\mathrm{Cp} *$ NMR resonance. Complex $\left[(\mathrm{Cp} * \mathrm{~W})_{3} \mathrm{O}_{4}(\mathrm{OH})_{2}\right]^{2+}$ does 
not show an NMR spectrum and displays an EPR signal, which is visible only at low temperature in a frozen glass matrix. The shape of the resonance shows an orthorhombically distorted tetragonal tensor, as expected for the slight perturbation of the $D_{3 h}$ symmetry by the asymmetric bridge system. Tungsten satellites were visible only in the parallel component, but their integration allowed to establish that the unpaired electron is coupled to only one $\mathrm{W}$ atom. The rationalization of this result was possible, as for the related Mo cluster (vide supra), by the DFT calculations. In fact, the symmetry lowering allows mixing between the $a\left(\mathrm{z}^{2}\right)$ and $e_{1}(x y)$ orbitals (both becoming $a^{\prime}$ in $C_{2}$ symmetry), with the result that the latter, where the unpaired electron resides, has a major component from only one $\mathrm{W}$ atom (spin density $=0.911$ ) and minor from the other two (spin density $=0.028$ and 0.036 ) [143].

A comparison of the results obtained for the reduction of $\left[\mathrm{Cp}_{2}{ }_{2} \mathrm{M}_{2} \mathrm{O}_{5}\right](\mathrm{M}=\mathrm{Mo}, \mathrm{W})$ under identical conditions shows, once again, a greater propensity of the Mo compound to be reduced: whereas reduction of the $\mathrm{W}$ compound stops at $\left[\left(\mathrm{Cp}^{*} \mathrm{~W}\right)_{3}(\mu-\mathrm{O})_{4}(\mu-\mathrm{OH})_{2}\right]^{2+}$ (a 3electron cluster) which is reoxidized in air to $\left[\left(\mathrm{Cp}^{*} \mathrm{~W}\right)_{3}(\mu-\mathrm{O})_{6}\right]^{+}$(a 2-electron cluster), the Mo system yields the 5-electron cluster $\left[\left(\mathrm{Cp}^{*} \mathrm{Mo}\right)_{3}(\mu-\mathrm{O})_{2}(\mu-\mathrm{OH})_{4}\right]^{2+}$. An exploration of the limits of redox stability of these systems as a function of $\mathrm{pH}$ (Pourbaix diagrams) has not yet been carried out.

Compound $\left[\mathrm{Cp}^{*}{ }_{2} \mathrm{Mo}_{2} \mathrm{O}_{5}\right]$ has also been reduced by compounds containing a S-H bond, namely $\mathrm{HS}\left(\mathrm{CH}_{2}\right)_{\mathrm{n}} \mathrm{COOH}(n=1,2)$ in an aqueous environment $\left(\mathrm{MeOH}-\mathrm{H}_{2} \mathrm{O}\right.$ acidified with $\left.\mathrm{CF}_{3} \mathrm{COOH}\right)[144,145]$. These reactions leads to very similar dinuclear products of $\mathrm{Mo}^{\mathrm{IV}}$ with formula $\left[\left(\mathrm{Cp}^{*} \mathrm{Mo}\right)_{2}\left(\mu-\mathrm{S}\left(\mathrm{CH}_{2}\right)_{\mathrm{n}} \mathrm{CO}_{2}\right)_{2}(\mu-\mathrm{E})\right]$, curiously differing by the nature of $\mathrm{E}$ ( $\mathrm{S}$ for $n=1$ [144] and $\mathrm{O}$ for $n=2$ [145]), see Scheme 10. The electrons for the reductions are provided by the S-H bonds, yielding compounds $\mathrm{HOOC}\left(\mathrm{CH}_{2}\right)_{n} \mathrm{SS}\left(\mathrm{CH}_{2}\right)_{n} \mathrm{COOH}$ which co-crystallize in each case with the organometallic product as H-bonded interstitial molecules. For the $n=1$ reaction, however, the substrate (thioglycolic acid) reacts not only as a reducing agent and as 
a ligand, but also as a substrate for reductive $\mathrm{C}-\mathrm{S}$ bond activation, furnishing the bridging sulfido ligand [144].

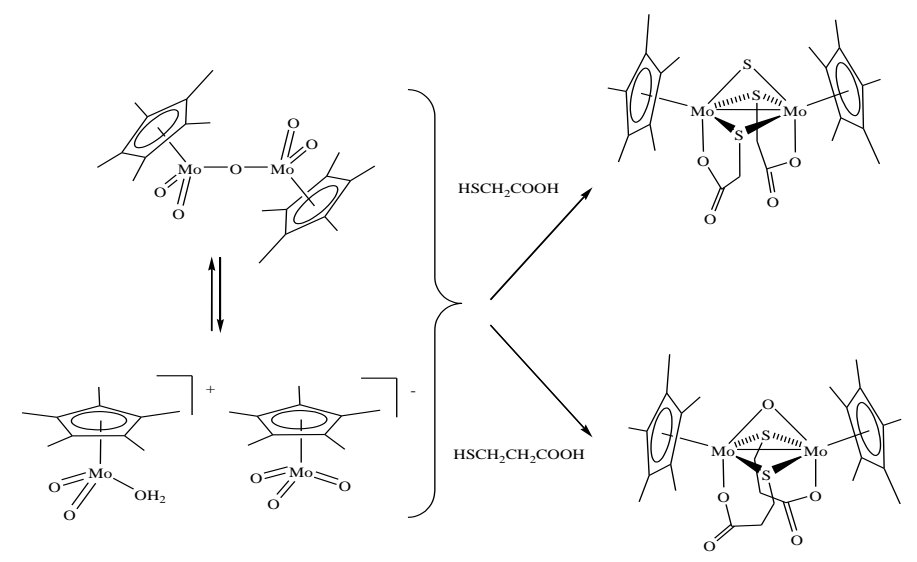

Scheme 10

\subsection{Other reactions}

The vast majority of other reactivity studies on cyclopentadienyl molybdenum and tungsten derivatives involve the "inorganic" part of the molecule. They are carried out in many cases under anhydrous conditions. When protic reagents or solvents are used, the transformation generally leaves the cyclopentadienylmetal moiety (and any M-alkyl bonds that may be present) intact.

\section{M-oxido exchange with water.}

This reaction has been investigated in detail for compound $\left[\mathrm{Cp} * \mathrm{MoO}_{2} \mathrm{Cl}\right]$ using $\mathrm{H}_{2}{ }^{18} \mathrm{O}$. The $\mathrm{O}$ exchange process takes place rather rapidly $\left(\mathrm{t}_{1 / 2} \sim 30 \mathrm{~min}\right)$, whereas no observable exchange occurs for alkyl derivatives, $\left[\mathrm{Cp} * \mathrm{MoO}_{2} \mathrm{R}\right]$ (e.g. $\mathrm{R}=\mathrm{CH}_{3}$, Scheme 11), over several days. This suggests that the initial step is a $\mathrm{Cl} / \mathrm{OH}$ exchange via a hydrogen-bonded intermediate (II), followed by intramolecular proton transfer, see Scheme 11Erreur ! Source 
du renvoi introuvable., whereas the alkyl derivative may only undergo a less favourable associative exchange via a dihydroxido intermediate [102].

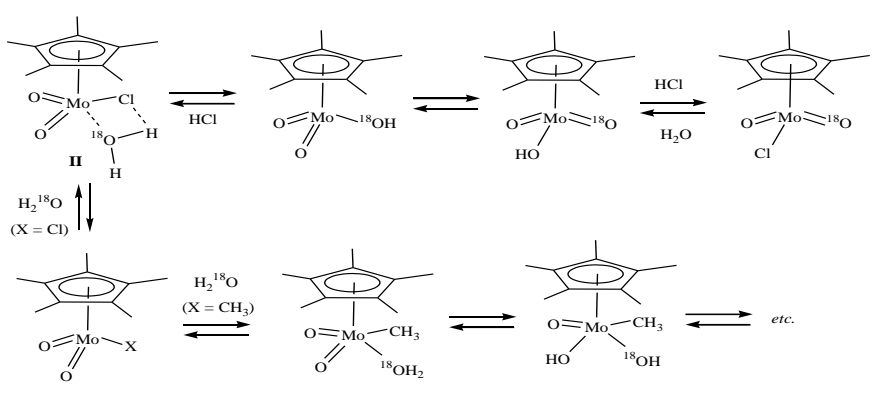

Scheme 11

A recent theoretical analysis on the cationic $\left[\mathrm{Cp}^{*} \mathrm{MoO}_{3} \mathrm{H}_{2}\right]^{+}$system, prompted by the observation of a slow intramolecular proton transfer leading from the $\left[\mathrm{Cp}^{*} \mathrm{MoO}(\mathrm{OH})_{2}\right]^{+}$ transient to the more stable $\left[\mathrm{Cp}^{*} \mathrm{MoO}_{2}\left(\mathrm{H}_{2} \mathrm{O}\right)\right]^{+}$isomer (see section 4.2), has shown that the intramolecular proton transfer is strongly assisted by external water molecules through a relay mechanism. The direct transfer involves a severe geometric distortion in the transition state (TS) in order to allow the proton jump (Scheme $12, \mathrm{TS}_{\mathrm{A}}, 43.1 \mathrm{kcal} / \mathrm{mol}$ relative to the reagents), whereas the involvement of one water molecule allows a less severe rearrangement $\left(\mathrm{TS}_{\mathrm{B}}, 12.7 \mathrm{kcal} / \mathrm{mol}\right)$ and two water molecules yield an even lower barrier of $1.3 \mathrm{kcal} / \mathrm{mol}$ for $\mathrm{TS}_{\mathrm{C}}[123]$

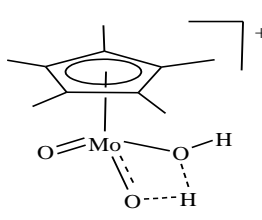

$\mathrm{TS}_{\mathrm{A}}$

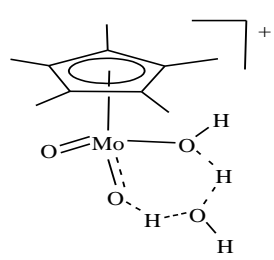

$\mathrm{TS}_{\mathrm{B}}$

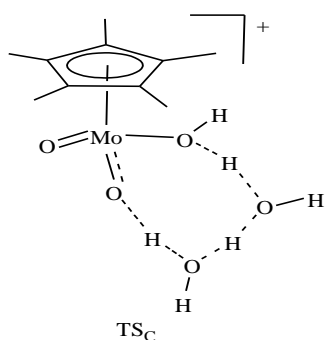

Scheme 12

Protonolysis of M-ligand bonds (M-Halogen, $M$-Alkyl, $M=N R, M=S, \ldots)$ 
Many hydrolytic processes involving M-halogen bonds have already been detailed within section 4.1, as they provide convenient syntheses of oxido derivatives that are commonly used as starting materials for other transformations. It is to be noted that $\mathrm{M}^{\mathrm{VI}}-\mathrm{Cl}$ are hydrolytically more sensitive than $\mathrm{M}^{\mathrm{VI}}=\mathrm{NR}$ or $\mathrm{M}^{\mathrm{VI}}=\mathrm{S}$ bonds, allowing selective transformations such as the conversion of $\left[\mathrm{Cp}^{*} \mathrm{~W}(\mathrm{~N} t \mathrm{Bu}) \mathrm{Cl}_{2}\right]$ to $[\mathrm{Cp} * \mathrm{~W}(\mathrm{~N} t \mathrm{Bu})(\mathrm{O}) \mathrm{Cl}]$ (in moist air) [91] and that of $\left[\mathrm{Cp}^{*} \mathrm{WS}_{2} \mathrm{Cl}\right]$ to $\left[\mathrm{Cp}^{*} \mathrm{WOS}_{2}\right]^{-}$(with small amounts of $\mathrm{H}_{2} \mathrm{O}$ ) [122].

Other reactions worthy of note for $\mathrm{M}$-halogen bonds are those of $\mathrm{Cp}^{*} \mathrm{MCl}_{4}$ with silanetriols and organosilyltriamide, summarized in Scheme 13, which were intended to generate model compounds of catalytic metals anchored on silica surfaces [146]. Even the use of 2 equivalents of $\mathrm{ArSi}\left(\mathrm{NH}_{2}\right)_{3}$ and excess $\mathrm{NEt}_{3}$ leads to the formation of the same product, which involves an interesting bond rearrangement and is a remarkably stable compound. The cyclic $\mathrm{Mo}^{\mathrm{V}}$ derivative obtained with $\operatorname{ArSi}(\mathrm{OH})_{3}$, on the other hand, can be easily oxidized to an acyclic $\mathrm{Mo}^{\mathrm{VI}}$ product. The Mo-Br bond in compound $\left[\left(\mathrm{C}_{5} \mathrm{Ph}_{4}(2,5-\right.\right.$ $\left.\left.\left.\mathrm{C}_{6} \mathrm{H}_{3}(\mathrm{OMe})_{2}\right)\right) \mathrm{MoO}_{2} \mathrm{Br}\right]$ is protonolyzed by aliphatic alcohols (but not phenols) to generate the corresponding $\left[\left(\mathrm{C}_{5} \mathrm{Ph}_{4}\left(2,5-\mathrm{C}_{6} \mathrm{H}_{3}(\mathrm{OMe})_{2}\right)\right) \mathrm{MoO}_{2}(\mathrm{OR})\right][87]$.

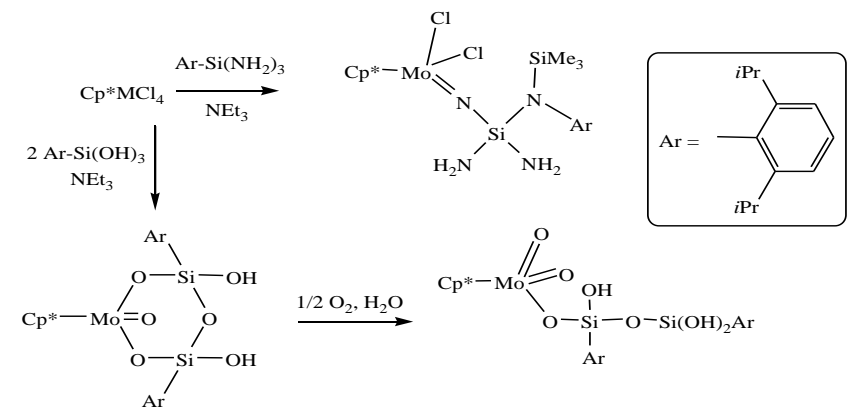

\section{Scheme 13}

Protonolysis of $\mathrm{M}-\mathrm{Cl}$ bonds with amines has been reported for $\left[\mathrm{Cp}^{*} \mathrm{WCl}_{4}\right]$, leading to $\left[\mathrm{Cp} * \mathrm{~W}(\mathrm{~N} t \mathrm{Bu}) \mathrm{Cl}_{2}\right]$ with $t \mathrm{BuNH}_{2}$ in the absence of air and to $\left[\mathrm{Cp} * \mathrm{~W}(\mathrm{NNHPh})_{2} \mathrm{Cl}\right]$ with $\mathrm{PhNHNH}_{2}$ in the presence of air. In this respect, this behaviour is analogous to the hydrolysis 
reaction, which yields oxido- $\mathrm{Mo}^{\mathrm{V}}$ and dioxido-Mo ${ }^{\mathrm{VI}}$ products in the absence or presence of air, respectively (see section 4.1) [91].

The $\mathrm{M}-\mathrm{Cl}$ bonds in $\left[\mathrm{Cp}^{*} \mathrm{MCl}_{4}\right](\mathrm{M}=\mathrm{Mo}, \mathrm{W})$ are also protonolyzed by $\mathrm{H}_{2} \mathrm{~S}$ in air, yielding mixtures of $[\mathrm{Cp} * \mathrm{MS}(\mu-\mathrm{S})]_{2}$ and $\left[\left(\mathrm{Cp}^{*} \mathrm{MS}\right)_{2}\left(\mu-\mathrm{S}_{2}\right)\right]$. In the presence of $\mathrm{NEt}_{3}$, however, the $\mathrm{W}$ compound affords $\left[\mathrm{Cp}^{*} \mathrm{WS}_{3}\right]^{-}$and $\left[\mathrm{Cp}^{*} \mathrm{WS}_{2} \mathrm{O}\right]^{-}$in addition to reduced yields of the above dinuclear compounds [91].

Protonolysis of M-alkyl bonds is not a very facile process, as expected from the high bond covalency (see Introduction). Compounds $\left[\mathrm{Cp} * \mathrm{M}\left(\mathrm{CH}_{3}\right)_{4}\right]$ do not react with water or silanols at room temperature, but do so upon slight warming [147]. The reaction with water leads to the products shown in Scheme 14, which were structurally characterized. Note that the metal center is formally reduced in the Mo reaction, whereas no oxidation state change occurs for $\mathrm{W}$. The same product for $\mathrm{W}$ was also obtained from the reaction with a silanetriol, whereas the corresponding reaction for the Mo system gave a mixture of uncharacterized products [147]. The same reagents undergo faster protonolysis with stronger acids, for instance $\mathrm{CF}_{3} \mathrm{SO}_{3} \mathrm{H}$ rapidly produces $\left[\mathrm{Cp} * \mathrm{M}\left(\mathrm{CH}_{3}\right)_{3}\left(\mathrm{O}_{3} \mathrm{SCF}_{3}\right)\right]$ at room temperature $[100,148]$. The $\mathrm{W}^{\mathrm{VI}}$ complex $\left[\mathrm{Cp} * \mathrm{~W}\left(\mathrm{CH}_{3}\right)_{4}\right]^{+}$reacts in ether with hydrazine to yield an adduct which deprotonates to a hydrazido product without cleaving the $\mathrm{W}-\mathrm{CH}_{3}$ bonds, $\left[\mathrm{Cp}^{*} \mathrm{~W}\left(\mathrm{CH}_{3}\right)_{4}\left(\mathrm{NHNH}_{2}\right)\right]$. The latter, however, is unstable and decomposes with methane evolution in polar solvents such as $\mathrm{CH}_{2} \mathrm{Cl}_{2}$, yielding [ $\mathrm{Cp} * \mathrm{~W}\left(\mathrm{CH}_{3}\right)_{3}\left(=\mathrm{NNH}_{2}\right)$ ] [99]. The presence of good donor ancillary ligands appears to render the $\mathrm{M}^{\mathrm{VI}}$-alkyl bonds more resistant to heterolytic splitting by strong acids. For instance, compounds $\left[\mathrm{Cp} * \mathrm{M}(\mathrm{N} t \mathrm{Bu})_{2}\left(\mathrm{CH}_{3}\right)\right]$ react with $\mathrm{HCl} / \mathrm{Et}_{2} \mathrm{O}$ to protonolyze the $\mathrm{M}=\mathrm{N} t \mathrm{Bu}$ bond, whereas the $\mathrm{M}-\mathrm{CH}_{3}$ bond remains intact [149]. 


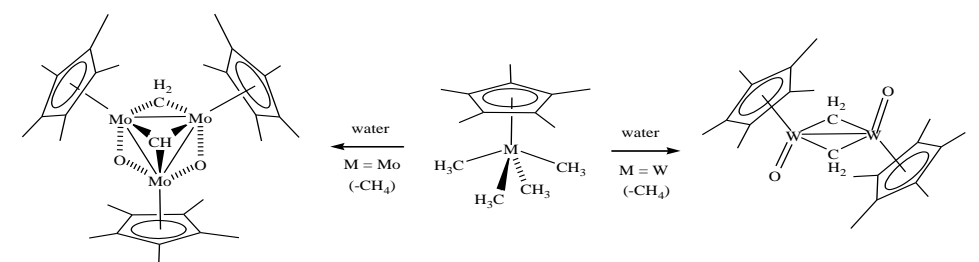

Scheme 14

The reaction of compounds $\left[\mathrm{Cp}{ }^{\prime} \mathrm{Mo}(\mathrm{NAr})_{2}\right]_{2}$ in wet $\mathrm{CHCl}_{3}$ slowly affords $\left[\mathrm{Cp}_{2}{ }_{2} \mathrm{Mo}_{2} \mathrm{O}(\mathrm{NAr})_{3}\right]\left(\mathrm{Cp}^{\prime}=\mathrm{C}_{5} \mathrm{R}_{\mathrm{n}} \mathrm{H}_{5-\mathrm{n}}\right.$ as shown in Scheme 15$)$, whereas use of diluted $\mathrm{HCl}$ in acetone rapidly leads to $\left[\mathrm{Cp}_{2}{ }_{2} \mathrm{Mo}_{2} \mathrm{O}_{2}(\mathrm{NAr})_{2}\right]$ where the residual imido ligands selectively occupy the bridging positions. Further efforts to replace the bridging imido ligands with oxido ligands have been unfruitful [150]. In contrast with this behaviour, the bridging imido ligand in the mixed-bridge $\left[\left(\mathrm{C}_{5} \mathrm{H}_{4} \mathrm{Me}\right)_{2} \mathrm{Mo}_{2} \mathrm{O}_{2}(\mu-\mathrm{O})(\mu-\mathrm{NPh})\right]$ compound is hydrolyzed by aqueous $\mathrm{HCl}$ or $\mathrm{CF}_{3} \mathrm{COOH}$, the reaction apparently involving an initial attach to a terminal oxido ligand to afford $\left[\left(\mathrm{C}_{5} \mathrm{H}_{4} \mathrm{Me}\right)_{2} \mathrm{Mo}_{2} \mathrm{O}(\mathrm{OH})(\mu-\mathrm{O})(\mu-\mathrm{NPh})\right]$ and ultimately giving $\left[\left(\mathrm{C}_{5} \mathrm{H}_{4} \mathrm{Me}\right)_{2} \mathrm{Mo}_{2} \mathrm{O}_{4}\right]$ [151]. The hydrolysis of $\mathrm{M}=\mathrm{NAr}$ functions has also been reported for mononuclear derivatives, e.g. $\left[\mathrm{Cp}^{*} \mathrm{M}\left(\mathrm{NR}^{\prime}\right)_{2} \mathrm{R}\right]\left(\mathrm{M}=\mathrm{Mo}, \mathrm{W} ; \mathrm{R}=\mathrm{Me}, \mathrm{Ph} ; \mathrm{R}^{\prime}=t \mathrm{Bu}\right)$ sequentially affords mixed oxido-imido derivatives $\left[\mathrm{Cp}^{*} \mathrm{MO}(\mathrm{NR}) \mathrm{R}\right]$ and dioxide derivatives $\left[\mathrm{Cp} * \mathrm{MO}_{2} \mathrm{R}\right][149]$.

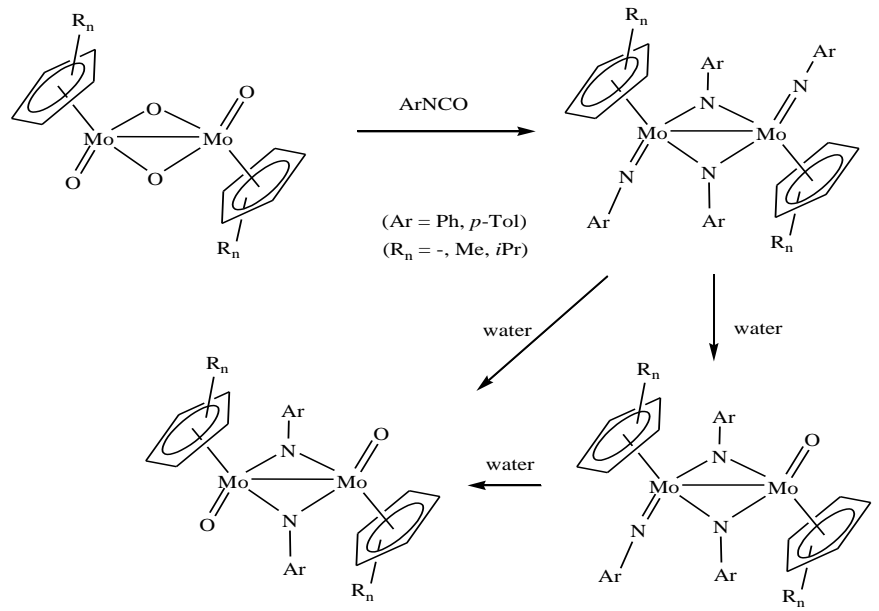

Scheme 15 
Interestingly, hydrolysis of $\left[\left(\mathrm{C}_{5} \mathrm{H}_{4} \mathrm{Me}\right)_{2} \mathrm{Mo}_{2} \mathrm{OS}(\mu-\mathrm{O})(\mu-\mathrm{NPh})\right]$ in hot wet toluene involves replacement of the sulfido ligand, yielding $\left[\left(\mathrm{C}_{5} \mathrm{H}_{4} \mathrm{Me}\right)_{2} \mathrm{Mo}_{2} \mathrm{O}_{2}(\mu-\mathrm{O})(\mu-\mathrm{NPh})\right]$, whereas the replacement of the phenylimido ligand occurs when the process is carried out with aqueous $\mathrm{HCl}$ in acetone, yielding $\left[\left(\mathrm{C}_{5} \mathrm{H}_{4} \mathrm{Me}\right)_{2} \mathrm{Mo}_{2} \mathrm{O}_{2}(\mu-\mathrm{O})(\mu-\mathrm{S})\right][151]$. On the other hand, the reaction of $\left[\mathrm{Cp}^{*} \mathrm{WS}_{3}\right]^{-}$with small amounts of water causes partial decomposition but the formation of mononuclear oxido-sulfido complexes was not discernible [122].

\section{Electrophilic addition to $M=O$ bonds}

The anionic complexes $\left[\mathrm{Cp}^{*} \mathrm{MO}_{3}\right]^{-}(\mathrm{M}=\mathrm{Mo}, \mathrm{W})$ have relatively nucleophilic oxido ligands. They exhibit an increased reactivity relative to neutral $\mathrm{Cp}^{*} \mathrm{ReO}_{3}$. Besides the protonation process leading to $\left[\mathrm{Cp}^{*}{ }_{2} \mathrm{M}_{2} \mathrm{O}_{5}\right]$ (see section 4.1), remarkable processes are the displacement of halido ligands from other metals to form oxido-bridged bimetallic compounds, [Cp* $\left.\mathrm{MO}_{2}(\mu-\mathrm{O}) \mathrm{ML}_{\mathrm{n}}\right]$ (e.g. $\left.\mathrm{ML}_{\mathrm{n}}=\mathrm{Cp}_{2} \mathrm{VCl}, \mathrm{Cp}_{2} \mathrm{TiCl}, \mathrm{Cp} 2 \mathrm{ZrCl}\right)[152,153]$. Addition to $\left[\mathrm{Cp}^{*} \mathrm{M}^{\prime} \mathrm{O}_{2} \mathrm{Cl}\right]\left(\mathrm{M}^{\prime}=\mathrm{Mo}, \mathrm{W}\right)$ readily leads to the mixed-metal $\left[\mathrm{Cp}^{*}(\mathrm{O})_{2} \mathrm{M}(\mu-\right.$ $\mathrm{O}) \mathrm{M}^{\prime} \mathrm{O}_{2} \mathrm{Cp}^{*}$ ], but the NMR analyses of both reactions (both possible choices of $\mathrm{M}$ and $\mathrm{M}^{\prime}$ ) indicates contamination by the homometallic complexes [153]. Addition of the W derivative to the rhenium alkylidyne complex $\left[\mathrm{CpRe}(\mathrm{CO})_{2}(\equiv \mathrm{CTol})\right]^{+}$involves the alkylidyne carbon atom, yielding the alkylidene derivative $\left[\mathrm{CpRe}(\mathrm{CO})_{2}\left(=\mathrm{C}(\mathrm{Tol}) \mathrm{OWO}_{2} \mathrm{Cp}^{*}\right]\right.$. Treatment with $\left[\mathrm{Ph}_{3} \mathrm{C}\right]^{+}$yields $\left[\mathrm{Cp} * \mathrm{WO}_{2}\left(\mathrm{OCPh}_{3}\right)\right][152]$ and a variety of $\mathrm{R}_{3} \mathrm{ECl}$ reagents $(\mathrm{E}=\mathrm{Si}, \mathrm{Ge}, \mathrm{Sn})$ afford the corresponding $\left[\mathrm{Cp} * \mathrm{WO}_{2}\left(\mathrm{OER}_{3}\right)\right]$ products [153]. One Mo analogue, $\left[\mathrm{Cp}^{*} \mathrm{MoO}_{2}\left(\mathrm{OSiBz}_{3}\right)\right]$, has also been described. The tin derivative exists in the form of a tetramer, see Scheme 16, due to the basicity of the oxido ligand and the tendency of tin(IV) to form hypervalent, 5 coordinate structures. 

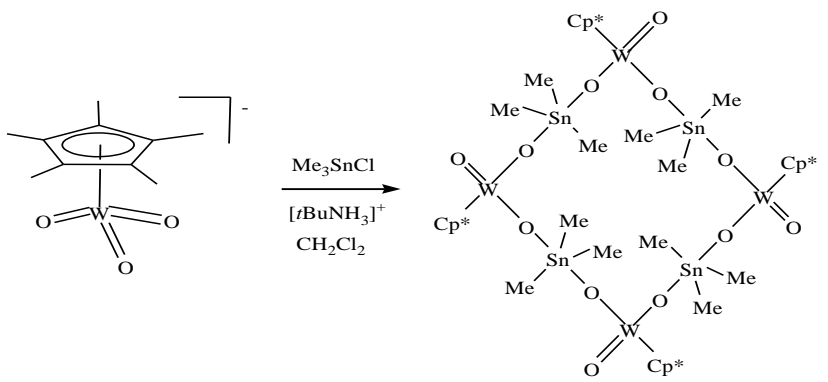

Scheme 16

The reaction of $\left[\mathrm{Cp}^{*} \mathrm{MoO}_{3}\right]^{-}$with $\mathrm{Ph}_{3} \mathrm{BiBr}_{2}$, on the other hand, gives rise to a $\mathrm{Mo}^{\mathrm{VI}}-\mathrm{O}-\mathrm{Bi}^{\mathrm{V}}-\mathrm{O}-$ $\mathrm{Mo}^{\mathrm{VI}}$ framework in compound $\left[\left(\mathrm{Cp}^{*} \mathrm{MoO}_{3}\right)_{2} \mathrm{BiPh}_{3}\right]$ [154]. Corresponding complexes with a $\mathrm{Mo}^{\mathrm{VI}}-\mathrm{O}-\mathrm{Bi}^{\mathrm{III}}$ framework could not be made using $\mathrm{Ph}_{2} \mathrm{BiBr}$, but the alternative use of $[(o-$ $\left.\mathrm{Tol})_{2} \mathrm{Bi}(\mathrm{hmpa})_{2}\right]\left(\mathrm{O}_{3} \mathrm{SCF}_{3}\right) \quad\left(\mathrm{hmpa}=\right.$ hexamethylphosphoric acid triamide, $\left.\mathrm{O}=\mathrm{P}\left(\mathrm{NMe}_{2}\right)_{3}\right)$, which is a protected form of the $\left[(o-\mathrm{Tol})_{2} \mathrm{Bi}\right]^{+}$cation, afforded the coordination polymer III (Scheme 17) [154]. The polymeric structure in this compound could be broken up by further addition of $\left[\mathrm{Cp}^{*} \mathrm{MoO}_{3}\right]^{-}$, yielding an isolated $\mathrm{Mo}^{\mathrm{VI}}-\mathrm{O}-\mathrm{Bi}{ }^{\mathrm{III}}-\mathrm{O}-\mathrm{Mo}^{\mathrm{VI}}$ framework in compound $\left[\left(\mathrm{Cp}^{*} \mathrm{MoO}_{3}\right)_{2} \mathrm{Bi}(o-\mathrm{Tol})_{2}\right]^{-}[155]$. On the other hand, addition of $\mathrm{OH}^{-}$(as aqueous $n \mathrm{Bu} 4 \mathrm{NOH}$ solution) to the same polymer displaces $\left[\mathrm{Cp}^{*} \mathrm{MoO}_{3}\right]^{-}$and yields $(o-\mathrm{Tol})_{2} \mathrm{Bi}(\mathrm{OH})$ [156], indicating the greater affinity of $\mathrm{OH}^{-}$relative to $\left[\mathrm{Cp}^{*} \mathrm{MoO}_{3}\right]^{-}$for $\mathrm{Bi}^{\mathrm{III}}$. These compounds have been studied as molecular models of the heterogeneous $\mathrm{MoO}_{3} / \mathrm{Bi}_{2} \mathrm{O}_{3}$ catalysts for the allylic oxidation of propene. Additions of $\left[\mathrm{Cp}^{*} \mathrm{WO}_{3}\right]^{-}$to phenylketene, $\mathrm{PhCH}=\mathrm{C}=\mathrm{O}$, and to MeOOCC $\equiv \mathrm{CCOOMe}$, leading to metallacycles, have also been reported [91].
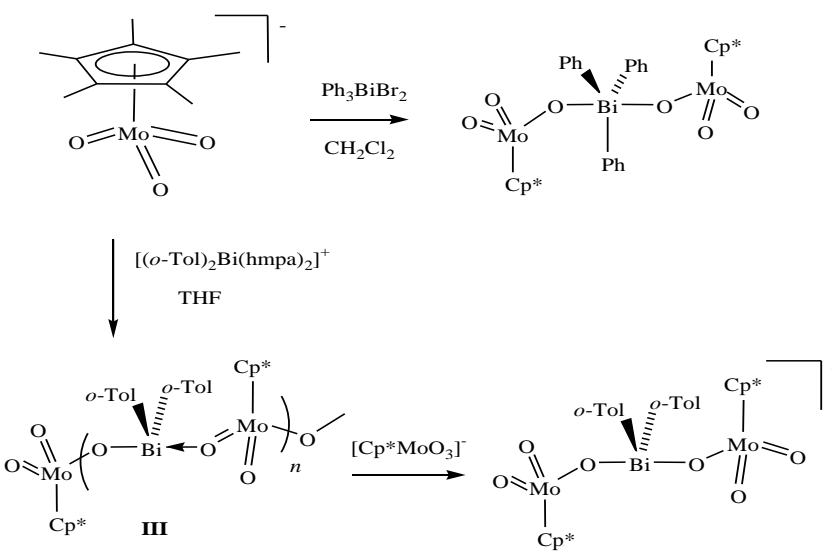


\section{Scheme 17}

Complex $\left[\mathrm{Cp}^{*} \mathrm{WS}_{3}\right]^{-}$also displays nucleophilic reactivity, being alkylated by $\mathrm{BzBr}$ and MeI to yield $\left[\mathrm{Cp}^{*} \mathrm{WS}_{2}(\mathrm{SR})\right]$ products $(\mathrm{R}=\mathrm{Bz}, \mathrm{Me})$. It also adds to acetylenes $(\mathrm{RCCH}, \mathrm{R}=$ $\mathrm{Ph}, \mathrm{H})$ to form ene-dithiolate complexes of $\mathrm{W}^{\mathrm{IV}}$, [Cp*WS(SCH=CRS)] ${ }^{-}[119]$.

Replacement of $M=O$ and $M=N R$ bonds with $M-X$ bonds $(X=$ halogen $)$.

This reaction is usually accomplished with $\mathrm{HX}$ (gas or $\mathrm{Et}_{2} \mathrm{O}$ solution) or $\mathrm{Me}_{3} \mathrm{SiX}$ reagents under anhydrous conditions, because water hydrolyses the Mo-X bonds to $\mathrm{Mo}=\mathrm{O}$ bonds, as shown in a preceding section. The reaction has been realized on both $\mathrm{Mo}^{\mathrm{VI}}$ and $\mathrm{Mo}^{\mathrm{V}}$ complexes. Thus, treatment of $\left[\mathrm{Cp}_{2} \mathrm{Mo}_{2} \mathrm{O}_{4}\right]$ or $\left[\mathrm{CpMoOX}_{2}\right]$ with $\mathrm{HX}$ gas affords $\left[\mathrm{CpMoX}_{4}\right](\mathrm{X}=\mathrm{Cl}, \mathrm{Br})[9,68]$. The resistance of the $\mathrm{Cp}-\mathrm{Mo}$ in these reactions is remarkable, although the aggressiveness of $\mathrm{HX}$ as a proton donor is lower in the gas phase than in aqueous solution. Analogously, treatment of $\left[\left(\mathrm{Cp}^{*} \mathrm{MoOCl}\right)_{2}(\mu-\mathrm{O})\right]$ with $\mathrm{Me}_{3} \mathrm{SiCl}$ affords [Cp* $\left.\mathrm{MoOCl}_{2}\right]$ [92]. Although $\left[\mathrm{Cp}_{2} \mathrm{Mo}_{2} \mathrm{O}_{4}\right]$ is oxidized by $\mathrm{Ag}_{2} \mathrm{O}$ to $\left[\mathrm{Cp}_{2} \mathrm{Mo}_{2} \mathrm{O}_{5}\right]$ and by $\mathrm{Br}_{2}$ to [CpMoO$\left.{ }_{2} \mathrm{Br}\right]$ [71], the $\mathrm{I}_{2}$ addition yields another $\mathrm{Mo}^{\mathrm{V}}$ derivative, $\left[\mathrm{Cp}_{2} \mathrm{Mo}_{2} \mathrm{O}_{3} \mathrm{I}_{2}\right]$, which has been structurally characterized [157].

Treatment with $\mathrm{HCl} / \mathrm{Et}_{2} \mathrm{O}$ also converts compounds $\left[\mathrm{Cp} * \mathrm{WO}_{2} \mathrm{R}\right]\left(\mathrm{R}=\mathrm{CH}_{3}, \mathrm{CH}_{2} \mathrm{SiMe}_{3}\right)$ to $\left[\mathrm{Cp}^{*} \mathrm{WOCl}_{2} \mathrm{R}\right]$, further alkylation of which afforded mixed alkyl derivatives [Cp*WORR' ${ }_{2}$ ] $[103,107]$. An analogous reaction on the Mo derivatives has not been described. On the other hand, the same reagent converts $\left[\mathrm{Cp} * \mathrm{MO}_{2} \mathrm{Cl}\right]$ to $\left[\mathrm{Cp}^{*} \mathrm{MOCl}_{3}\right][102]$ and $\left[\mathrm{Cp} * \mathrm{M}(\mathrm{N} t \mathrm{Bu})_{2} \mathrm{Me}\right]$ to $\left[\mathrm{Cp} * \mathrm{M}(\mathrm{N} t \mathrm{Bu}) \mathrm{Cl}_{2} \mathrm{Me}\right]\left(\mathrm{R}=\mathrm{Me} ; \mathrm{R}^{\prime}=t \mathrm{Bu}\right)$ [149] for both Mo and $\mathrm{W}$.

\section{Replacement of $M=O$ with $M=N R$ bonds.}

The exchange with imido ligands is conveniently realized by reaction with isocyanates. For instance, the dinuclear $\mathrm{Mo}^{\mathrm{V}}$ derivatives $\left[\mathrm{Cp}^{\prime} \mathrm{MoO}(\mu-\mathrm{O})\right]_{2}\left(\mathrm{Cp}^{\prime}=\mathrm{C}_{5} \mathrm{H}_{4} \mathrm{R} ; \mathrm{R}=\mathrm{H}, \mathrm{Me}, i \mathrm{Pr}\right)$, afford $\left[\mathrm{Cp} \mathrm{p}^{\mathrm{M}} \mathrm{Mo}(\mathrm{NAr})(\mu-\mathrm{NAr})\right]_{2}[150,158]$. The reaction with lower amounts of isocyanates is 
not a clean entry into mixed oxido-imido derivatives, which may be obtained by controlled hydrolysis of the fully imido-substituted products (vide supra). Exchange processes at the terminal $\mathrm{Mo}=\mathrm{NAr}$ positions for other NAr' (from Ar'NCO) have been reported, whereas the bridging positions are inert [159]. Related mixed oxido-imido derivatives of type $\left[\mathrm{Cp}_{2}{ }_{2} \mathrm{Mo}_{2} \mathrm{O}_{2}(\mu-\mathrm{O})(\mu-\mathrm{NAr})\right]$, containing only one bridging imido ligand, have been obtained by another strategy, namely oxidation of triply-bonded $\left[\mathrm{Cp}_{2}{ }_{2} \mathrm{Mo}_{2}(\mathrm{CO})_{4}\right]$ with $\mathrm{ArNO}_{2}[160$, 161].

\section{Replacement of $M=O$ with $M=S$ bonds.}

This reaction is carried out with $\mathrm{H}_{2} \mathrm{~S}$ and generally no more than one $\mathrm{O}$ atom per metal is replaced. For instance, compound $\left[\left(\mathrm{C}_{5} \mathrm{H}_{4} \mathrm{Me}\right)_{2} \mathrm{Mo}_{2} \mathrm{O}_{2}(\mu-\mathrm{O})(\mu-\mathrm{NPh})\right]$ yields $\left[\left(\mathrm{C}_{5} \mathrm{H}_{4} \mathrm{Me}\right)_{2-}\right.$ $\left.\mathrm{Mo}_{2} \mathrm{OS}(\mu-\mathrm{O})(\mu-\mathrm{NPh})\right][151]$ and $\left[\mathrm{Cp}^{*} \mathrm{MO}_{2} \mathrm{R}\right]\left(\mathrm{M}=\mathrm{Mo}, \mathrm{W} ; \mathrm{R}=\mathrm{Me}, \mathrm{CH}_{2} \mathrm{SiMe}_{3}\right)$ yield the corresponding $\left[\mathrm{Cp}^{*} \mathrm{MO}(\mathrm{S}) \mathrm{R}\right][162]$. However, whereas the reaction stops at the mixed oxidosulfido product for the two trimethylsilylmethyl derivatives and for the W-Me compound, the Mo-Me compound reacts further to yield an unstable disulfido derivative, which is readily oxidized to form a stable product containing a $\eta^{2}-\mathrm{S}_{2} \mathrm{O}$ ligand, see Scheme 18.

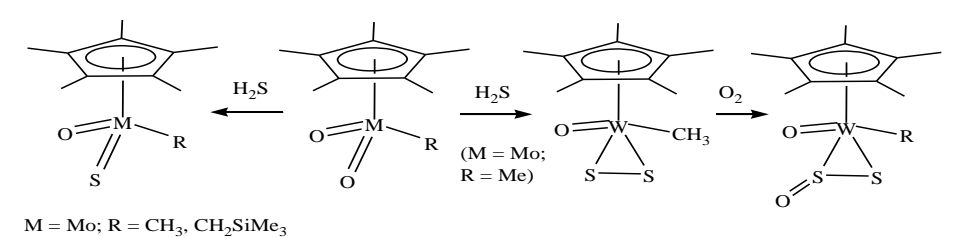

$$
\mathrm{M}=\mathrm{Mo} ; \mathrm{R}=\mathrm{CH}_{3}, \mathrm{CH}_{2} \mathrm{SiMe}_{3}
$$

\section{Scheme 18}

\section{Peroxidation reaction}

For certain specific compounds, oxido ligands may be converted to peroxido ligands upon treatment with $\mathrm{H}_{2} \mathrm{O}_{2}$ or organic hydroperoxides (mostly TBHP) or peroxides. A convenient reagent is peroxidized diethyl ether, which is obtained by exposing diethyl ether to 
air and is used as both reagent and solvent. The utility of the latter reagent was demonstrated for the transformation of $\left[\mathrm{Cp}^{*} \mathrm{MoO}_{2} \mathrm{Cl}\right]$ to $\left[\mathrm{Cp} * \mathrm{MO}\left(\mathrm{O}_{2}\right) \mathrm{Cl}\right](\mathrm{M}=\mathrm{Mo}, \mathrm{W})$ [102]. Wet methods involve the complication of the $\mathrm{Mo}-\mathrm{Cl}$ bond hydrolysis leading to to $\left[\mathrm{Cp}^{*}{ }_{2} \mathrm{M}_{2} \mathrm{O}_{5}\right]$, although this is not very fast under neutral conditions. Therefore, the peroxido product could also be obtained using aqueous $30 \% \mathrm{H}_{2} \mathrm{O}_{2}$, but timing was essential to minimize the hydrolysis side reaction. The more common $t \mathrm{BuOOH}$ reagent, on the other hand, does not readily effect this particular peroxidation reaction. Peroxidized diethyl ether turns out to be the most effective reagent [102], the reactions being complete over $24 \mathrm{~h}$ at room temperature. However, a later study showed that TBHP smoothly converts $\left[\mathrm{Cp}^{*} \mathrm{MoO}_{2} \mathrm{Cl}\right]$ to $\left[\mathrm{Cp} * \mathrm{MoO}\left(\mathrm{O}_{2}\right) \mathrm{Cl}\right]$ in toluene at $45^{\circ} \mathrm{C}(71 \%$ isolated yields after $4 \mathrm{~h})$ [86]. Other alkylhydroperoxides such as cumene hydroperoxide and $\mathrm{Ph}_{3} \mathrm{COOH}$ also effect this transformation, whereas $n$-hexyl hydroperoxide failed to yield the desired product, leading instead to uncharacterized insoluble white materials with formation of $n$-hexyl alcohol. An even more recent study shows that complexes $\left[\mathrm{Cp} * \mathrm{MCl}_{4}\right]$ can be converted directly and in high isolated yields ( $85 \%$ for $\mathrm{Mo}, 80 \%$ for $\mathrm{W}$ ) to $\left[\mathrm{Cp} * \mathrm{MO}\left(\mathrm{O}_{2}\right) \mathrm{Cl}\right]$ by using $30 \%$ aqueous $\mathrm{H}_{2} \mathrm{O}_{2}$ in diethyl ether [163].

An ${ }^{18} \mathrm{O}$ labelling study showed that $\left[\mathrm{Cp} * \mathrm{MoO}\left(\mathrm{O}_{2}\right) \mathrm{Cl}\right]$ exchanges with $\mathrm{H}_{2}{ }^{18} \mathrm{O}$ selectively into the oxido position. Furthermore, reaction of ${ }^{18} \mathrm{O}$-labelled $\left[\mathrm{Cp} * \mathrm{MoO}_{2} \mathrm{Cl}\right]$ with unlabelled peroxide-containing and $\mathrm{H}_{2}{ }^{18} \mathrm{O}$-saturated diethyl ether yields $\left[\mathrm{Cp} * \mathrm{MoO}\left(\mathrm{O}_{2}\right) \mathrm{Cl}\right]$ with no ${ }^{18} \mathrm{O}$ label in the peroxido ligand. This clearly demonstrates that the O-O bond of the organoperoxide remains intact during the reaction and in the final product [102]. Thus, formation of the peroxido ligand occurs by ligand exchange rather than by oxygen atom transfer.

As detailed in section 4.1, the peroxidation reaction is particularly easy for alkyl derivatives. Thus, peroxide derivatives are obtained in good yields by addition of $\mathrm{H}_{2} \mathrm{O}_{2}$ or TBHP to tricarbonyl adducts [98, 108, 109]. 


\section{Cleavage of the Cp-M bond}

A rare example of a reaction where the $\mathrm{Cp} * \mathrm{Mo}$ is cleaved heterolytically (albeit very slowly) was revealed during an attempt to crystallize a salt of the $\left[\mathrm{Cp} * \mathrm{MoO}_{2}\left(\mathrm{H}_{2} \mathrm{O}\right)\right]^{+}$cation, which was generated by dissolving $\left[\mathrm{Cp}^{*}{ }_{2} \mathrm{Mo}_{2} \mathrm{O}_{5}\right]$ in water at low $\mathrm{pH}$. A solution of this cation, left unprotected from air and sunlight for several weeks, led to the deposition of crystals of compound $\left[\mathrm{Cp}^{*}{ }_{2} \mathrm{Mo}_{6} \mathrm{O}_{17}\right]$ [164]. The $\mathrm{W}$ analogue, obtained by a non-aqueous route, has also been reported [165]. The compound is a member of the isoelectronic family of polyoxometallates, $\left[(\mathrm{Cp} * \mathrm{Mo})_{\mathrm{n}}(\mathrm{MoO})_{6-\mathrm{n}} \mathrm{O}_{13}\right]^{(\mathrm{n}-2)-}$, of which those with $n=0[166]$ and $1[85$, 139] are also known. As already mentioned in a previous section, the unsubstituted analogue, $\left[\mathrm{Cp}_{2} \mathrm{Mo}_{2} \mathrm{O}_{5}\right]$, does not resist an aqueous environment for a long time, even at $\mathrm{pH} 7$ [79], but the nature of the resulting products has not been investigated in detail.

While going from $\mathrm{Cp}$ to the sterically more encumbered and electronically more donating $\mathrm{Cp}^{*}$ greatly increases the stability of all $\mathrm{Mo}^{\mathrm{VI}}$ compounds in water (with respect to protonolysis of the cyclopentaidneyl-molybdenum bond), moving further on to the even more sterically encumbering but electronically less donating $\mathrm{C}_{5} \mathrm{Ph}_{4}\left(2,5-\mathrm{C}_{6} \mathrm{H}_{3}(\mathrm{OMe})_{2}\right)$ greatly labilizes the interaction with the metal. Thus, compound $\left[\left(\mathrm{C}_{5} \mathrm{Ph}_{4}\left(2,5-\mathrm{C}_{6} \mathrm{H}_{3}(\mathrm{OMe})_{2}\right)\right)\right.$ $\left.\mathrm{MoO}_{2}(\mathrm{OMe})\right]$ leads to a mixture of products, some of which could not be characterized, when treated with water, acetic acid, or 4-methoxyphenol. However, all these reactions yielded variable amounts of the free cyclopentadiene, $\mathrm{C}_{5} \mathrm{Ph}_{4}\left(2,5-\mathrm{C}_{6} \mathrm{H}_{3}(\mathrm{OMe})_{2}\right) \mathrm{H}$, this being isolated in high yields when using a large excess of water in the reaction [87]. Loss of this ring has also been observed during catalytic cyclooctene epoxidation. Given the established reactivity with aliphatic alcohols (vide supra), the reaction between $\left[\left(\mathrm{C}_{5} \mathrm{Ph}_{4}\left(2,5-\mathrm{C}_{6} \mathrm{H}_{3}(\mathrm{OMe})_{2}\right)\right) \mathrm{MoO}_{2} \mathrm{Br}\right]$ and TBHP is presumed to afford $\left[\left(\mathrm{C}_{5} \mathrm{Ph}_{4}\left(2,5-\mathrm{C}_{6} \mathrm{H}_{3}(\mathrm{OMe})_{2}\right)\right) \mathrm{MoO}_{2}(\mathrm{OO} t \mathrm{Bu})\right]$ which serves as an active catalyst. However, NMR monitoring shows that all NMR signals of the coordinated ring are lost and no new peaks grow that could be attributed to another $\left(\mathrm{C}_{5} \mathrm{Ph}_{4}(2,5-\right.$ 
$\left.\left.\mathrm{C}_{6} \mathrm{H}_{3}(\mathrm{OMe})_{2}\right)\right) \mathrm{Mo}^{\mathrm{VI}}$ species or to the free cyclopentadiene, $\mathrm{C}_{5} \mathrm{Ph}_{4}\left(2,5-\mathrm{C}_{6} \mathrm{H}_{3}(\mathrm{OMe})_{2}\right) \mathrm{H}$. Yet, at the point in which all starting compound is fully decomposed, the catalytic oxidation continues at even faster rate [167]. Therefore, a new and cyclopentadienyl-free species, the nature of which is not yet elucidated, must be an even better catalyst for olefin epoxidation. This finding serves as a warning that even systems believed to be extremely robust toward protonolysis of the cyclopentadienyl-molybdenum bond, may undergo slight decomposition with loss of the organic ligand, even in trace amounts, to afford a more active molybdenum species.

\section{Condensations to form organometallic polyoxometallates}

Compound $\left[\mathrm{Cp}_{2}{ }_{2} \mathrm{Mo}_{6} \mathrm{O}_{17}\right]$, serendipitously obtained as described in the previous section, was also prepared directly and selectively by the condensation of $\left[\mathrm{Cp}^{*}{ }_{2} \mathrm{Mo}_{2} \mathrm{O}_{5}\right]$ and $\mathrm{Na}_{2} \mathrm{MoO}_{4}$ in the appropriate stoichiometric ratio in acidic aqueous solution, see Scheme 19 [164]. The related $\left[\mathrm{Cp}^{*} \mathrm{Mo}_{6} \mathrm{O}_{18}\right]^{-}$ion (the $n=1$ member of the above mentioned series) was obtained as the $\left[\mathrm{C}_{5} \mathrm{Me}_{5} \mathrm{O}\right]^{+}$salt as a by-product of the aerial oxidation of $\left[\mathrm{Cp} * \mathrm{Mo}(\mathrm{CO})_{2}\right]_{2}$ in $\mathrm{CHCl}_{3}[85]$ and as the $\left[n \mathrm{Bu}_{4} \mathrm{~N}\right]^{+}$salt by condensation between $\left[n \mathrm{Bu}_{4} \mathrm{~N}\right]\left[\mathrm{Cp}^{*} \mathrm{MoO}_{3}\right]$ and $\left[n \mathrm{Bu}_{4} \mathrm{~N}\right]_{2}\left[\mathrm{Mo}_{4} \mathrm{O}_{10}(\mathrm{OMe})_{4} \mathrm{Cl}_{2}\right]$ in $\mathrm{MeOH}$ [139]. This condensation strategy between organometallic and inorganic components appears to be general. Compounds $\left[(\mathrm{LM})(\mathrm{MoO})(\mu-\mathrm{O})_{3}\right]_{4}\left[\mathrm{LM}=\mathrm{Cp}^{*} \mathrm{Rh}\right.$ and $\left.\left(p-\mathrm{MeC}_{4} \mathrm{H}_{4} i \mathrm{Pr}\right) \mathrm{Ru}\right]$ were also obtained in water from $\mathrm{Na}_{2} \mathrm{MoO}_{4}$ and $\left[\mathrm{Cp} * \mathrm{RhCl}_{2}\right]_{2}$ [168] or $\left[\left(p-\mathrm{MeC}_{4} \mathrm{H}_{4} i \mathrm{Pr}\right) \mathrm{RuCl}_{2}\right]_{2}$ [169], respectively. Mixedmetal clusters, $\left[\left(\mathrm{Cp}^{*} \mathrm{Rh}\right)_{3}\left(\left(p-\mathrm{MeC}_{4} \mathrm{H}_{4} i \mathrm{Pr}\right) \mathrm{Ru}\right)(\mathrm{MoO})_{4}(\mu-\mathrm{O})_{12}\right]$ and $\left[(\mathrm{Cp} * \mathrm{Rh})_{2}\left(\left(p-\mathrm{MeC}_{4} \mathrm{H}_{4} i \mathrm{Pr}\right)-\right.\right.$ $\left.\mathrm{Ru})_{2}(\mathrm{MoO})_{4}(\mu-\mathrm{O})_{12}\right]$, were also obtained [170]. More recently, compounds $\left[\left(\left(\eta^{6}-\right.\right.\right.$ arene $\left.) \mathrm{Ru})_{4}(\mathrm{WO})_{4}(\mu-\mathrm{O})_{12}\right]$ (arene $\left.=\mathrm{C}_{6} \mathrm{Me}_{6}, p \mathrm{MeC}_{6} \mathrm{H}_{4} i \mathrm{Pr}\right)$ where obtained similarly from $\mathrm{Na}_{2} \mathrm{WO}_{4}$ and $\left[\left(\eta^{6} \text {-arene }\right) \mathrm{RuCl}_{2}\right]_{2}$, although the reaction was conducted in acetonitrile [171]. Compound $\left[\left(\left(\eta^{6} \text {-arene }\right) \mathrm{Ru}\right)_{4}\left(\mathrm{WO}_{2}\right)_{2}(\mu-\mathrm{O})_{6}\right]$ was also obtained as a by-product. The organic 
ligands in these compounds are on the $\mathrm{Rh}$ or $\mathrm{Ru}$ atoms, whereas the high oxidation state Mo or $\mathrm{W}$ centers are inorganic.

$$
\left[\mathrm{Cp}_{2}{ }_{2} \mathrm{Mo}_{2} \mathrm{O}_{5}\right]+4 \mathrm{MoO}_{4}{ }^{2-}+8 \mathrm{H}^{+} \underset{-4 \mathrm{H}_{2} \mathrm{O}}{\longrightarrow}
$$

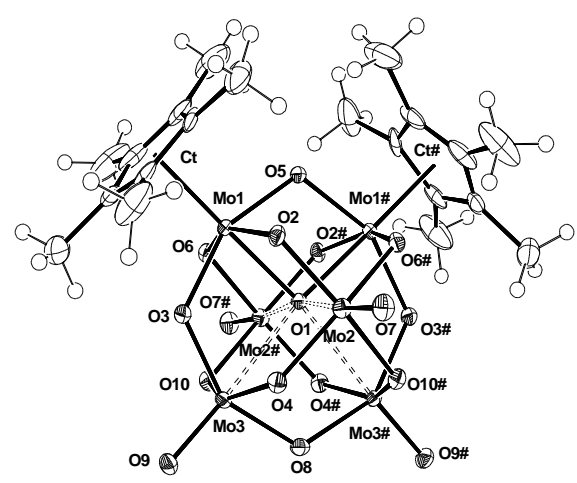

Scheme 19

Other condensation processes using high oxidation state organometallic Group 6 metal complexes and other reagents have been conducted in anhydrous media, for instance the reaction between $\left[\mathrm{Cp}^{*} \mathrm{WO}_{2}(\mathrm{C} \equiv \mathrm{CPh})\right]$ and $\left[\mathrm{Ru}_{4}(\mathrm{CO})_{13}\left(\mu_{3}-\mathrm{PPh}\right)\right]$ in refluxing toluene yields mainly $\left[\left(\mathrm{Cp}^{*} \mathrm{WO}_{2}\right) \mathrm{Ru}_{4}(\mathrm{CO})_{10}\left(\mu_{4}-\mathrm{PPh}\right)(\mathrm{C} \equiv \mathrm{CPh})\right]$ with small amounts of $\left[\left(\mathrm{Cp}^{*} \mathrm{WO}_{2}\right) \mathrm{Ru}_{4}(\mathrm{CO})_{7-}\right.$ $\left.\left(\mathrm{C}_{7} \mathrm{H}_{8}\right)\left(\mu_{4}-\mathrm{PPh}\right)(\mathrm{C} \equiv \mathrm{CPh})\right]$ and $\left[\left(\mathrm{Cp}^{*} \mathrm{WO}_{2}\right) \mathrm{Ru}_{5}(\mathrm{CO})_{12}\left(\mathrm{C}_{7} \mathrm{H}_{8}\right)\left(\mu_{4}-\mathrm{PPh}\right)(\mathrm{C} \equiv \mathrm{CPh})\right]$ [172], whereas the same W complex reacts with $\left[\mathrm{Os}_{3}(\mathrm{CO})_{10}(\mathrm{MeCN})_{2}\right]$ yields $\left[\left(\mathrm{Cp}^{*} \mathrm{WO}_{2}\right) \mathrm{Oss}_{3}(\mathrm{CO})_{9}(\mathrm{C} \equiv \mathrm{CPh})\right]$ [173].

\section{Conclusion}

The heavier group 6 metals have an extensive and rich organometallic chemistry in protic media. The more extensively investigated $\mathrm{Cp}^{*} \mathrm{Mo}$ and $\mathrm{Cp} * \mathrm{~W}$ system have demonstrated a particular robustness of the $\mathrm{Cp}^{*} \mathrm{M}$ bond and its compatibility with water in a variety of oxidation states and with proton donors of different strengths (down to $\mathrm{pH} 0$ in water for the $\mathrm{Cp}^{*} \mathrm{Mo}^{\mathrm{VI}}$ system). Alkyl and aryl derivatives (in cyclopentadienyl-free systems) 
have been much less investigated and $\pi$-allyl systems are completely unexplored, but a rich chemistry may be anticipated for these systems in protic media. The majority of the transformations observed for these organometallic compounds concern the rest of the coordination sphere, the $\mathrm{M}-\mathrm{C}$ bonds remaining intact, especially for the higher-hapticity cyclopentadienyl derivatives. This feature allows the use of organic substituents for compatibilizing high oxidation state metal centers with organic media and for blocking a certain number of coordination positions (e.g. three for cyclopentadienyl ligands), thereby limiting or eliminating aggregation processes (e.g. formation of high-nuclearity polyoxometallates in acidic media). New catalytic applications in aqueous or biphasic environment may therefore be envisaged. Coming back to a proposition made in the introduction, the envisaged generation of open coordination sites by conversion of oxido ligands to aqua ligands upon metal reduction has already been demonstrated. In fact, even the $\mathrm{Cp}^{*} \mathrm{Mo}^{\mathrm{VI}}$ system where the metal is in the highest oxidation state generates an open coordination site at low $\mathrm{pH}$ (rapid equilibrium between $\left[\mathrm{Cp}^{*} \mathrm{MoO}_{2}\left(\mathrm{H}_{2} \mathrm{O}\right)\right]^{+}$and $\left[\mathrm{Cp}^{*} \mathrm{MoO}_{2}\right]^{+}$ in water) [123]. Upon reduction, compounds $\left[\mathrm{Cp}^{*}{ }_{2} \mathrm{M}_{2} \mathrm{O}_{5}\right](\mathrm{M}=\mathrm{Mo}, \mathrm{W})$ yield $\left[\left(\mathrm{Cp}^{*} \mathrm{Mo}\right)_{3} \mathrm{O}_{2}(\mathrm{OH})_{4}\right]^{2+}$ or $\left[(\mathrm{Cp} * \mathrm{~W})_{3} \mathrm{O}_{4}(\mathrm{OH})_{2}\right]^{2+}$ with expulsion of a number of $\mathrm{O}$ atoms as water $[141,143]$. The reduced metal centres in these clusters assemble in a triangular fashion in order to share electrons and bridging ligands, thereby saturating their coordination sphere, but the $\mathrm{M}(\mu-\mathrm{OH}) \mathrm{M}$ bridge opening process (perhaps after an additional protonation) appears feasible by a number of substrates. The interaction of these reduced clusters with different substrates and a study of their activation and transformation, possibly leading to catalytic and electrocatalytic reduction processes, seems a promising research avenue for further investigations.

\section{Acknowledgement}


Work on this project in my own laboratory has been supported by the CNRS, by CINES and CICT (Project CALMIP) for the DFT calculations, and by the European Commission through the AQUACHEM program (contract HPRN-CT-2002-00176). Additional funding from the Institut Universitaire de France is also gratefully acknowledged. The AQUACHEM program has led to a number of fruitful collaborations (Rudi van Eldik in Erlangen, Agustí Lledós in Barcelona, Ovadia Lev and Jenny Gun in Jerusalem, Maurizio Peruzzini in Florence, Armando Pombeiro in Lisbon) that I have greatly appreciated. I also thoroughly enjoy the continuing collaboration with Prof. Funda Demirhan (Celal Bayar University, Manisa), which has been supported by bilateral CNRS-TUBITAK funds and by the French Ministry of Foreign Affairs.

\section{References}

[1] A. J. Shortland, G. Wilkinson, J. Chem. Soc., Dalton Trans. (1973) 872.

[2] K. Mertis, G. Wilkinson, J. Chem. Soc., Dalton Trans. (1976) 1488.

[3] W. A. Herrmann, R. Serrano, A. Schäfer, U. Küsthardt, M. L. Ziegler, E. Guggolz, J. Organometal. Chem. 272 (1984) 55.

[4] W. A. Herrmann, J. G. Kuchler, G. Weichselbaumer, E. Herdweck, P. Kiprof, J. Organometal. Chem. 372 (1989) 351.

[5] K. Köhler, A. Herzog, A. Steiner, H. W. Roesky, Angew. Chem., Int. Ed. Engl. 35 (1996) 295.

[6] C. J. Longley, P. D. Savage, G. Wilkinson, B. Hussain, M. B. Hursthouse, Polyhedron 7 (1988) 1079.

[7] W. A. Herrmann, S. Bogdanovic, R. Poli, T. Priermeier, J. Am. Chem. Soc. 116 (1994) 4989.

[8] M. L. H. Green, J. Organometal. Chem. 500 (1995) 127.

[9] M. Cousins, M. L. H. Green, J. Chem. Soc. (A) (1969) 16.

[10] M. Herberhold, W. Kremnitz, A. Razavi, H. Schöllhorn, U. Thewalt, Angew. Chem., Int. Ed. Eng. 24 (1985) 601.

[11] S. K. Noh, R. A. Heintz, B. S. Haggerty, A. L. Rheingold, K. H. Theopold, J. Am. Chem. Soc. 114 (1992) 1892.

[12] K. L. Breno, T. J. Ahmed, M. D. Pluth, C. Balzarek, D. R. Tyler, Coord. Chem. Rev. 250 (2006) 1141.

[13] G. Parkin, J. E. Bercaw, Polyhedron 7 (1988) 2053.

[14] G. Parkin, J. E. Bercaw, J. Am. Chem. Soc. 111 (1989) 391.

[15] G. Parkin, J. E. Bercaw, Organometallics 8 (1989) 1172.

[16] L. Y. Kuo, M. G. Kanatzidis, T. J. Marks, J. Am. Chem. Soc. 109 (1987) 7207.

[17] L. Y. Kuo, M. G. Kanatzidis, M. Sabat, A. L. Tipton, T. J. Marks, J. Am. Chem. Soc. 113 (1991) 9027.

[18] C. Balzarek, T. J. R. Weakley, L. Y. Kuo, D. R. Tyler, Organometallics 19 (2000) 2927. 
[19] J. B. Waern, C. T. Dillon, M. M. Harding, Journal of Medicinal Chemistry 48 (2005) 2093.

[20] P. Diversi, G. Ingrosso, G. Lucherini, M. Landucci, Polyhedron 6 (1987) 281.

[21] P. Jernakoff, J. R. Fox, J. C. Hayes, S. Lee, B. M. Foxman, N. J. Cooper, Organometallics 14 (1995) 4493.

[22] R. L. Thompson, M. D. Hopkins, N. J. Cooper, S. Lee, Organometallics 14 (1995) 1969.

[23] G. A. Miller, N. J. Cooper, J. Organometal. Chem. 528 (1997) 151.

[24] R. R. Schrock, Acc. Chem. Res. 19 (1986) 342.

[25] R. R. Schrock, Acc. Chem. Res. 23 (1990) 158.

[26] R. R. Schrock, Polyhedron 14 (1995) 3177.

[27] R. R. Schrock, Chem. Rev. 102 (2002) 145.

[28] A. Bino, F. A. Cotton, Z. Dori, J. Am. Chem. Soc. 103 (1981) 243.

[29] M. Ardon, A. Bino, F. A. Cotton, Z. Dori, M. Kaftory, B. W. S. Kolthammer, M. Kapon, G. Reisner, Inorg. Chem. 20 (1981) 4083.

[30] A. Bino, F. A. Cotton, Z. Dori, L. R. Falvello, G. M. Reisner, Inorg. Chem. 21 (1982) 3750 .

[31] A. Bino, M. Ardon, E. Shirman, Science 308 (2005) 234.

[32] P. M. Reis, C. C. Romão, B. Royo, J. Chem. Soc., Dalton Trans. (2006) 1842.

[33] C. Freund, M. Abrantes, F. E. Kühn, J. Organomet. Chem. 691 (2006) 3718.

[34] H. W. Roesky, I. Haiduc, N. S. Hosmane, Chem. Rev. 103 (2003) 2579.

[35] H. W. Roesky, S. Singh, K. K. M. Yusuff, J. A. Maguire, N. S. Hosmane, Chem. Rev. 106 (2006) 3813.

[36] K. H. Theopold, Topics Organomet. Chem. 22 (2007) 17.

[37] R. Poli, Chem. Eur. J. 10 (2004) 332.

[38] E. Collange, F. Demirhan, J. Gun, O. Lev, A. Modestov, R. Poli, P. Richard, D. Saurenz, Perspectives in Organometallic Chemistry, C. G. Screttas, Ed., Royal Society of Chemistry, 2003.

[39] F. E. Kühn, A. M. Santos, M. Abrantes, Chem. Rev. 106 (2006) 2455.

[40] B. Heyn, R. Hoffmann, Z. Chem. 16 (1976) 195.

[41] B. Heyn, R. Hoffmann, Z. Chem. 16 (1976) 407.

[42] J. R. M. Kress, M. J. M. Russell, M. G. Wesolek, J. A. Osborn, J. Chem. Soc., Chem. Comm. (1980) 431.

[43] P. Stavropoulos, G. Wilkinson, M. Motevalli, M. B. Hursthouse, Polyhedron 6 (1987) 1081.

[44] F. E. Kühn, A. M. Santos, A. D. Lopes, I. S. Goncalves, E. Herdtweck, C. C. Romao, J. Mol. Catal. A 164 (2000) 25.

[45] F. E. Kühn, M. Groarke, E. Bencze, E. Herdtweck, A. Prazeres, A. M. Santos, M. J. Calhorda, C. C. Romão, I. S. Gonçalves, A. D. Lopes, M. Pillinger, Chem. Eur. J. 8 (2002) 2370.

[46] C. Zhang, E. O. Schlemper, G. N. Schrauzer, Organometallics 9 (1990) 1016.

[47] C. Zhang, X. Zhang, N. H. Liu, G. N. Schrauzer, E. O. Schlemper, Organometallics 9 (1990) 1307.

[48] W. M. Vetter, A. Sen, Organometallics 10 (1991) 244.

[49] A. A. Valente, J. Moreira, A. D. Lopes, M. Pillinger, C. D. Nunes, C. C. Romao, F. E. Kuehn, I. S. Goncalves, New J. Chem. 28 (2004) 308.

[50] J. Sundermeyer, J. Putterlick, H. Pritzkow, Chem. Ber. 126 (1993) 289.

[51] M. Onishi, K. Ikemoto, K. Hiraki, R. Koga, Bull. Chem. Soc. Jpn. 66 (1993) 1849.

[52] Y. L. Wong, D. K. P. Ng, H. K. Lee, Inorg. Chem. 41 (2002) 5276.

[53] P. Legzdins, S. J. Rettig, L. Sánchez, Organometallics 4 (1985) 1470.

[54] G. N. Schrauzer, E. L. Moorehead, J. H. Grate, L. Hughes, J. Am. Chem. Soc. 100 (1978) 4760. 
[55] G. N. Schrauzer, L. A. Hughes, N. Strampach, Zeitschrift fuer Naturforschung, Teil B: Anorganische Chemie, Organische Chemie 37B (1982) 380.

[56] H. Arzoumanian, R. Lai, S. Lebot, M. Pierrot, F. Ridouane, Inorg. Chim. Acta 182 (1991) 173.

[57] G. N. Schrauzer, L. A. Hughes, N. Strampach, F. Ross, D. Ross, E. O. Schlemper, Organometallics 2 (1983) 481.

[58] B. Lane, K. Burgess, Chem. Rev. 103 (2003) 2457.

[59] M. Groarke, I. S. Gonçalves, W. A. Herrmann, F. E. Kühn, J. Organomet. Chem. 649 (2002) 108.

[60] J. Sundermeyer, J. Putterlik, H. Pritzkow, Chem. Ber. 126 (1993) 289.

[61] S. Jang, L. M. Atagi, J. M. Mayer, J. Am. Chem. Soc. 112 (1990) 6413.

[62] J. C. Bryan, J. B. Arterburn, G. K. Cook, J. M. Mayer, Organometallics 11 (1992) 3965.

[63] L. M. Atagi, S. C. Critchlow, J. M. Mayer, J. Am. Chem. Soc. 114 (1992) 1483.

[64] C. Borgmann, C. Limberg, E. Kaifer, H. Pritzkow, L. Zsolnai, J. Organometal. Chem. 580 (1999) 214.

[65] C. Borgmann, C. Limberg, S. Cunskis, P. Kircher, Eur. J. Inorg. Chem. (2001) 349.

[66] D. Morales, M. E. N. Clemente, J. Perez, L. Riera, V. Riera, D. Miguel, Organometallics 21 (2002) 4934.

[67] R. D. Ernst, Chem. Rev. 88 (1988) 1255.

[68] M. Cousins, M. L. H. Green, J. Chem. Soc. (1964) 1567.

[69] J. A. Segal, M. L. H. Green, J.-C. Daran, K. Prout, J. Chem. Soc., Chem. Commun. (1976) 766.

[70] W. L. Elcesser, M. Sorlie, J. L. Hubbard, Organometallics 15 (1996) 2534.

[71] M. J. Bunker, M. L. H. Green, J. Chem. Soc., Dalton Trans. (1981) 847.

[72] F. Bottomley, E. C. Ferris, P. S. White, Organometallics 9 (1990) 1166.

[73] T. Robin, F. Montilla, A. Galindo, C. Ruiz, J. Hartmann, Polyhedron 18 (1999) 1485.

[74] C. Couldwell, K. Prout, Acta Crystallogr. B34 (1978) 933.

[75] S. T. Krueger, B. E. Owens, R. Poli, Inorg. Chem. 29 (1990) 2001.

[76] M. L. H. Green, J. D. Hubert, P. Mountford, J. Chem. Soc., Dalton Trans. (1990) 3793.

[77] J. C. Gordon, R. Poli, Synthetic Methods of Organometallic and Inorganic Chemistry (Herrmann/Brauer), W. A. Herrmann, Ed., Georg Thieme Verlag, Stuttgart, 1997.

[78] D. Saurenz, F. Demirhan, P. Richard, R. Poli, H. Sitzmann, Eur. J. Inorg. Chem. (2002) 1415.

[79] C. Dinoi, Université Paul Sabatier, Toulouse, 2007.

[80] E. Collange, J. Garcia, R. Poli, New J. Chem. 26 (2002) 1249.

[81] J. W. Faller, Y. Ma, J. Organometal. Chem. 340 (1988) 59.

[82] A. L. Rheingold, J. R. Harper, J. Organometal. Chem. 403 (1991) 335.

[83] P. Leoni, M. Pasquali, L. Salsini, C. Di Bugno, D. Braga, P. Sabatino, J. Chem. Soc. Dalton Trans. (1989) 155.

[84] P. Gomez-Sal, E. De Jesus, P. Royo, A. Vazquez De Miguel, S. Martinez-Carrera, S. Garcia-Blanco, J. Organometal. Chem. 353 (1988) 191.

[85] F. Bottomley, J. Chen, Organometallics 11 (1992) 3404.

[86] M. B. Trost, R. G. Bergman, Organometallics 10 (1991) 1172.

[87] W. M. Harrison, C. Saadeh, S. B. Colbran, D. C. Craig, J. Chem. Soc., Dalton Trans. (1997) 3785.

[88] M. Abrantes, A. Santos, J. Mink, F. Kühn, C. Romão, Organometallics 22 (2003) 2112.

[89] A. M. Martins, C. C. Romão, M. Abrantes, M. C. Azevedo, J. Cui, A. R. Dias, M. T. Duarte, M. A. Lemos, T. Lourenço, R. Poli, Organometallics 24 (2005) 2582.

[90] K. Umakoshi, K. Isobe, J. Organometal. Chem. 395 (1990) 47. 
[91] M. S. Rau, C. M. Kretz, G. L. Geoffroy, A. L. Rheingold, Organometallics 12 (1993) 3447.

[92] F. Bottomley, P. D. Boyle, J. H. Chen, Organometallics 13 (1994) 370.

[93] J. Sundermeyer, U. Radius, C. Burschka, Chem. Ber. 125 (1992) 2379.

[94] R. C. Murray, L. Blum, A. H. Liu, R. R. Schrock, Organometallics 4 (1985) 953.

[95] D. W. Keogh, R. Poli, Synthetic Methods of Organometallic and Inorganic Chemistry (Herrmann/Brauer), W. A. Herrmann, Ed., Georg Thieme Verlag, Stuttgart, 1997.

[96] C. Dinoi, G. Taban, P. Sözen, F. Demirhan, J.-C. Daran, R. Poli, J. Organomet. Chem. 692 (2007) 3743-3749.

[97] C. D. Abernethy, F. Bottomley, J. Chen, M. F. Kemp, T. C. Mallais, O. O. Womiloju, Inorg. Synth. 32 (1998) 207.

[98] J. Zhao, A. M. Santos, E. Herdtweck, F. E. Kühn, J. Mol. Catal. A 222 (2004) 265.

[99] R. C. Murray, R. R. Schrock, J. Am. Chem. Soc. 107 (1985) 4557.

[100] R. R. Schrock, R. M. Kolodziej, A. H. Liu, W. M. Davis, M. G. Vale, J. Am. Chem. Soc. 112 (1990) 4338.

[101] J. W. Faller, Y. Ma, Organometallics 7 (1988) 559.

[102] J. W. Faller, Y. Ma, J. Organometal. Chem. 368 (1989) 45.

[103] P. Legzdins, E. C. Phillips, S. J. Rettig, L. Sánchez, J. Trotter, V. C. Yee, Organometallics 7 (1988) 1877.

[104] P. Legzdins, P. J. Lundmark, E. C. Phillips, S. J. Rettig, J. E. Veltheer, Organometallics 11 (1992) 2991.

[105] P. Legzdins, S. J. Rettig, K. J. Ross, J. E. Veltheer, J. Am. Chem. Soc. 113 (1991) 4361.

[106] P. Legzdins, S. J. Rettig, K. J. Ross, R. J. Batchelor, F. W. B. Einstein, Organometallics 14 (1995) 5579.

[107] P. Legzdins, E. C. Phillips, L. Sánchez, Organometallics 8 (1989) 940.

[108] C. W. Shiu, C. J. Su, C. W. Pin, Y. Chi, P. S. M. Peng, G. H. Lee, J. Organomet. Chem. 546 (1997) 151.

[109] R. Roberts, H. Puschmann, J. Howard, J. Yamamoto, A. Carty, P. Low, J. Chem. Soc., Dalton Trans. (2003) 1099.

[110] J. Zhao, E. Herdtweck, F. E. Kühn, J. Organomet. Chem. 691 (2006) 2199.

[111] M. Abrantes, A. Sakthivel, C. C. Romão, F. E. Kühn, J. Organomet. Chem. 691 (2006) 3137.

[112] G. S. B. Adams, M. L. H. Green, J. Chem. Soc., Dalton Trans. (1981) 353.

[113] J. C. Fettinger, H.-B. Kraatz, R. Poli, E. A. Quadrelli, J. Chem. Soc., Dalton Trans. (1999) 497.

[114] J. C. Fettinger, H.-B. Kraatz, R. Poli, E. A. Quadrelli, Chem. Commun. (1997) 889.

[115] D. Morales, B. Pleune, R. Poli, P. Richard, J. Organometal. Chem. 596 (2000) 64.

[116] B. Antelmann, G. Huttner, U. Winterhalter, J. Organometal. Chem. 555 (1998) 119.

[117] M. L. H. Green, P. C. Konidaris, P. Mountford, J. Chem. Soc., Dalton Trans. (1994) 2851.

[118] J. Sundermeyer, Chem. Ber. 124 (1991) 1977.

[119] H. Kawaguchi, K. Tatsumi, J. Am. Chem. Soc. 117 (1995) 3885.

[120] H. Kawaguchi, K. Yamada, J.-P. Lang, K. Tatsumi, J. Am. Chem. Soc. 119 (1997) 10346.

[121] H. Kawaguchi, K. Tatsumi, Chem. Commun. (2000) 1299.

[122] H. Kawaguchi, K. Tatsumi, Angew. Chem., Int. Ed. Eng. 40 (2001) 1266.

[123] J.-E. Jee, A. Comas-Vives, C. Dinoi, G. Ujaque, R. Van Eldik, A. Lledós, R. Poli, Inorg. Chem 46 (2007) 4103.

[124] R. G. Linck, B. E. Owens, R. Poli, A. L. Rheingold, Gazz. Chim. Ital. 121 (1991) 163.

[125] M. L. H. Green, P. Mountford, J. Chem. Soc., Chem. Commun. (1989) 732.

[126] J. C. Gordon, V. T. Lee, R. Poli, Inorg. Chem. 32 (1993) 4460. 
[127] F. Abugideiri, G. A. Brewer, J. U. Desai, J. C. Gordon, R. Poli, Inorg. Chem. 33 (1994) 3745.

[128] J. U. Desai, J. C. Gordon, H.-B. Kraatz, V. T. Lee, B. E. Owens-Waltermire, R. Poli, A. L. Rheingold, C. B. White, Inorg. Chem. 33 (1994) 3752.

[129] C. Cremer, P. Burger, J. Chem. Soc., Dalton Trans. (1999) 1967.

[130] H. Blackburn, J. C. Fettinger, H.-B. Kraatz, R. Poli, R. C. Torralba, J. Organometal. Chem. 593-594 (2000) 27.

[131] M. L. H. Green, P. C. Konidaris, P. Mountford, J. Chem. Soc., Dalton Trans. (1994) 2975.

[132] F. Bottomley, V. Sanchez, R. C. Thompson, O. O. Womiloju, Z. Q. Xu, Can. J. Chem. 78 (2000) 383.

[133] F. Bottomley, J. Chen, K. F. Preston, R. C. Thompson, J. Am. Chem. Soc. 116 (1994) 7989.

[134] P. Hofmann, N. Rosch, Chem. Commun. (1986) 843.

[135] P. Hofmann, N. Roesch, H. R. Schmidt, Inorg. Chem. 25 (1986) 4470.

[136] P. Kubácek, R. Hoffmann, Z. Havlas, Organometallics 1 (1982) 180.

[137] J. Gun, A. Modestov, O. Lev, D. Saurenz, M. A. Vorotyntsev, R. Poli, Eur. J. Inorg. Chem. (2003) 482.

[138] J. Gun, A. Modestov, O. Lev, R. Poli, Eur. J. Inorg. Chem. (2003) 2264.

[139] A. Proust, R. Thouvenot, P. Herson, J. Chem. Soc., Dalton Trans. (1999) 51.

[140] F. Demirhan, P. Richard, R. Poli, Inorg. Chim. Acta 347 (2003) 61.

[141] F. Demirhan, B. Çagatay, D. Demir, M. Baya, J.-C. Daran, R. Poli, Eur. J. Inorg. Chem. (2006) 757.

[142] F. Demirhan, J. Gun, O. Lev, A. Modestov, R. Poli, P. Richard, J. Chem. Soc, Dalton Trans. (2002) 2109.

[143] C. Dinoi, P. Sözen, G. Taban, D. Demir, F. Demirhan, P. Prikhodchenko, J. Gun, O. Lev, J.-C. Daran, R. Poli, Eur. J. Inorg. Chem. (2007) 4306.

[144] F. Demirhan, G. Taban, M. Baya, C. Dinoi, J.-C. Daran, R. Poli, J. Organometal. Chem. 691 (2006) 648.

[145] C. Dinoi, P. Prikhodchenko, F. Demirhan, J. Gun, O. Lev, J.-C. Daran, R. Poli, J. Organomet. Chem. 692 (2007) 2599.

[146] R. Siefken, M. Teichert, D. Chakraborty, H. W. Roesky, Organometallics 18 (1999) 2321.

[147] O. Guzyr, J. Prust, H. W. Roesky, C. Lehmann, M. Teichert, F. Cimpoesu, Organometallics 19 (2000) 1549.

[148] M. B. O'regan, A. H. Liu, W. C. Finch, R. R. Schrock, W. B. Davis, J. Am. Chem. Soc. $112(1990) 4331$.

[149] U. Radius, G. Wahl, J. Sundermeyer, Z. Anorg. Allg. Chem. 630 (2004) 848.

[150] M. L. H. Green, G. Hogarth, P. C. Konidaris, P. Mountford, J. Chem. Soc., Dalton Trans. (1990) 3781.

[151] J. Fletcher, G. Hogarth, D. A. Tocher, J. Organomet. Chem. 405 (1991) 207.

[152] M. S. Rau, C. M. Kretz, L. A. Mercando, G. L. Geoffroy, A. L. Rheingold, J. Am. Chem. Soc. 113 (1991) 7420.

[153] M. S. Rau, C. M. Kretz, G. L. Geoffroy, A. L. Rheingold, B. S. Haggerty, Organometallics 13 (1994) 1624.

[154] S. Roggan, C. Limberg, B. Ziemer, Angew. Chem., Int. Ed. Engl. 44 (2005) 5259.

[155] S. Roggan, C. Limberg, M. Brandt, B. Ziemer, J. Organomet. Chem. 690 (2005) 5282.

[156] S. Roggan, C. Limberg, B. Ziemer, M. Siemons, U. Simon, Inorg. Chem. 45 (2006) 9020.

[157] K. Prout, C. Couldwell, Acta Crystallogr. B36 (1980) 1481.

[158] M. L. H. Green, G. Hogarth, P. C. Konidaris, P. Mountford, J. Organomet. Chem. 394 (1990) C9. 
[159] G. Hogarth, P. C. Konidaris, J. Organomet. Chem. 399 (1990) 149.

[160] H. Alper, A. C. Willis, J. F. Petrignani, F. W. B. Einstein, J. Am. Chem. Soc. 105 (1983) 1701.

[161] J. Fletcher, G. Hogarth, D. A. Tocher, J. Organomet. Chem. 403 (1991) 345.

[162] J. W. Faller, Y. Ma, Organometallics 8 (1989) 609.

[163] D. Chakraborty, M. Bhattacharjee, R. Krätzner, R. Siefken, H. W. Roesky, I. Usón, H.-G. Schmidt, Organometallics 18 (1999) 106.

[164] E. Collange, L. Metteau, P. Richard, R. Poli, Polyhedron 23 (2004) 2605.

[165] J. R. Harper, A. L. Rheingold, J. Am. Chem. Soc. 112 (1990) 4037.

[166] J. Fuchs, K. F. Jahr, Z. Naturforsch., B: Chem. Sci. 23 (1968) 1380.

[167] M. Pratt, J. B. Harper, S. B. Colbran, J. Chem. Soc., Dalton Trans. (2007) 2746.

[168] Y. Hayashi, K. Toriumi, K. Isobe, J. Am. Chem. Soc. 110 (1988) 3666.

[169] G. Suss-Fink, L. Plasseraud, V. Ferrand, H. Stoeckli-Evans, Chem. Commun. (1997) 1657.

[170] G. Suss-Fink, L. Plasseraud, V. Ferrand, S. Stanislas, A. Neels, H. Stoeckli-Evans, M. Henry, G. Laurenczy, R. Roulet, Polyhedron 17 (1998) 2817.

[171] V. Artero, A. Proust, P. Herson, P. Gouzerh, Chem. Eur. J. 7 (2001) 3901.

[172] P. Blenkiron, A. J. Carty, S. M. Peng, G. H. Lee, C. J. Su, C. W. Shiu, Y. Chi, Organometallics 16 (1997) 519.

[173] C. W. Shiu, Y. Chi, A. J. Carty, S. M. Peng, G. H. Lee, Organometallics 16 (1997) 5368 